\title{
Travma Sonrası Büyümenin Yordayıcıları Olarak Olayın Etkisi ve İyimserlik
}

\author{
Seher Balcı Çelik* Nurdan Doğru Çabuker ${ }^{* *}$ Meryem Vural Batık ${ }^{* * *}$ Hatice Epli****
}

- Geliş Tarihi: 15.06.2021 • Kabul Tarihi: 24.01.2022 • Çevrimiçi Yayın Tarihi: 24.01.2022

\section{$\ddot{O} z$}

COVID salgını sürecinde birçok ülkede olduğu gibi Türkiye'deki üniversitelerde de uzaktan eğitim aracıllğıyla eğitim sürdürülmüştür. Bu dönemde üniversite öğrencilerinin travmatik bir yaşantı olarak kabul edilen salgın sürecinden ne kadar etkilendiği merak konusu olmuştur. $\mathrm{Bu}$ araştırmada öğretmen adaylarının COVID salgınının ve iyimserliğin travma sonrası büyüme üzerindeki yordayıcı etkilerini incelemek amaçlanmıştır. Araştırmanın çalışma grubunu Ondokuz Mayıs Üniversitesi’nde öğrenim gören ve uygun örnekleme yöntemiyle ulaş1lan 801 öğretmen aday1 oluşturmuştur. Veri toplama araçları olarak Olayların Etkisi Ölçeği, Travma sonrası Büyüme Envanteri ve İyimserlik Ölçeği kullanılmıştır. Pearson Momentler Çarpımı Korelasyon analizi sonuçları, travma sonrası büyümenin olayın etkisi ve iyimserlik ile pozitif yönde anlamlı ilişkili olduğunu; iyimserliğin ise olayın etkisi ile negatif yönde anlamlı ilişkili olduğunu ortaya koymuştur. Hiyerarşik regresyon analizi sonuçlarına göre, iyimserlik ve olayın etkisi değişkenlerinin travma sonrası büyümeyi anlamlı olarak yordadığı; travma sonrası büyümenin \%31'ini açıkladığı belirlenmiştir. Tek Yönlü MANOVA sonucuna göre, kadın öğretmen adaylarının COVID salgınından erkek öğretmen adaylarına göre anlamlı ölçüde daha çok etkilendiği ve kadın öğretmen adaylarının travma sonrası büyüme düzeylerinin erkek öğretmen adaylarına göre anlamlı ölçüde daha yüksek olduğu saptanmıştır.

Anahtar sözcükler: Öğretmen adayı, travma sonrası büyüme, olayın etkisi, iyimserlik, pandemi.

\section{Atıf:}

Balcı Çelik, S., Doğru Çubuker, N, Vural Batık, M. ve Epli, H. (2022). Travma sonrası büyümenin yordayıc1ları olarak olayın etkisi ve iyimserlik. Pamukkale Üniversitesi Eğitim Fakültesi Dergisi, 55, 180-202.doi:10.9779.pauefd.952783

\footnotetext{
* Prof. Dr., Ondokuz Mayıs Üniversitesi Eğitim Fakültesi Eğitim Bilimleri Bölümü, sbalci@omu.edu.tr-0000-0001-95066528

** Dr., Ondokuz Mayıs Üniversitesi Eğitim Fakültesi, nurdan.cabuker@omu.edu.tr-0000-0001-7976-8829

*** Doç. Dr., Ondokuz Mayıs Üniversitesi Eğitim Fakültesi Özel Eğitim Bölümü, meryem.vural@omu.edu.tr-0000-00027836-7289

**** Dr. Öğr. Üyesi, Ondokuz Mayıs Üniversitesi Eğitim Fakültesi Eğitim Bilimleri Bölümü, hatice.epli@omu.edu.tr0000-0001-9122-1922
} 


\section{Giriş}

2019 yılının Aralık ayında Çin'de ortaya çıkan COVID salgını haftalar içinde tüm dünyayı etkisi altına almıştır. 11 Mart 2019'da Türkiye'de ilk vakanın görülmesiyle tüm dünyada olduğu gibi Türkiye’de de salgınla mücadele edebilmek adına bir dizi önlemler alınmıştır. Özel ve resmi iş yerlerinde esnek ve dönüşümlü çalışmaya geçilmiş, sokağa çıkma yasakları getirilmiştir. Alışveriş merkezleri, sinema salonları ve restoran gibi insan yoğunluğunun fazla olduğu sosyal alanlar kapatılmış, tüm kademelerdeki okullarda uzaktan eğitime geçilmiştir. Salgının hızla yayılması, izolasyon önlemleri, üniversitelerde uzaktan eğitime geçiş (Cao vd., 2020) ve uzaktan eğitim sistemindeki yetersizlikler (Karadağ ve Yücel, 2020) öğrencilerin ruh sağlı̆̆ını olumuz etkilemiştir. Üniversite öğrenimine devam eden yükseköğretim öğrencilerinin, içinde bulundukları gelişim dönemi ve gelişimsel görevleri dikkate alındığında, alınan tedbirler ve getirilen yeni düzenlemelerden en çok etkilenen gruplardan biri olduğu düşünülmektedir.

Sosyal yaşamda bir anda meydana gelen büyük değişim ve salgının beraberinde getirdiği kayıp ihtimali (Yeşildal ve Reyhanlıoğlu, 2020), fiziksel veya yaşamsal bütünlüğe yönelik bir tehdidin ortaya çıkması, ölüm veya ölüm tehdidinin bulunması (Ezerbolat ve Özpolat, 2016), doğal afetler, cinsel taciz veya tecavüze maruz kalma, ölümcül bir hastalık tanısı almak, terör saldırıları, salgınlar, kazalar ve sevilen birinin kaybı gibi olaylar (Altan, 2013; Bellur, 2015; Yeşildal ve Reyhanlıŏglu, 2020) travma olarak tanımlanmaktadır. COVID salgını boyunca bireylerin kendileri ve yakınlarının sağlığı için duydukları endişe, salgının seyrine ve tedavisine yönelik belirsizlik, virüs bulaşan yakınlarını ziyaret edememek ya da kayıp yaşayan yakınlarının acılarını paylaşamamak travmadır (Yeşildal ve Reyhanlığlu, 2020). Ancak travmaların bireylerin yaşamlarına negatif etkileri olduğu gibi pozitif etkileri de olabilmektedir (Arıkan, 2007).

Olumsuz yaşam olaylarının ardından bireylerde meydana gelen olumlu değişimler, travma sonrası büyüme olarak ifade edilmektedir (Tedeschi ve Calhoun, 2004). Travmatik yaşantılar bireylerin her ne kadar olumsuz yaşantılar geçirmelerine neden olsa da bireylerin yaşama dair bakış açılarını genişleterek, bireysel ve sosyal kaynaklarını fark etmelerini sağlamaktadır (Park ve Fenster, 2004). Travma sonrası büyümenin yaşandığı alanlar her bireyde farklı düzeylerde ortaya çıkabilir. Travma sonrası yaşanan büyüme, bireyin kendilik algısında, ilişkilerinde ve yaşam felsefesinde olmak üzere üç alanda ortaya çıkmaktadır (Güven, 2010; Tedeschi, Park ve Calhoun, 1998). Travma sonras1 bireyler, incinebilirliklerine, ölümlülüklerine ve güçlü yönlerine dair farkındalık kazanarak, yaşamın 
182 S. B. Çelik, N. D. Çabuker, M. V. Batık ve H. Epli/ Pamukkale Üniversitesi Eğitim Fakültesi Dergisi, 55, 180-202, 2022 değerini anlamış bireyler olarak karşımıza çıkmaktadırlar. Kendilerine yönelik kazandıkları farkındalıklar, başkalarına karşı hassasiyet, empati ve şefkat duygularını güçlendirir (Tedeschi vd., 1998). Var olan ilişkileri için gösterdikleri çabada ve yardım etme eğiliminde artış yaşanmaktadır (Haselden, 2014). Travmanın ardından bireyler hayatın değerini sorgulayarak, yaşam önceliklerinde değişim meydana gelebilir ve daha önce farkında olmadıkları şeyler için şükran duyabilirler (Tedeschi, vd., 1998). Tarım (2019) yaptığ1 çalışmada, yaşamın değerini fark etme, ilişkilerde yaşanan olumlu dönüşümler, yüksek dayanıklık, içsel dönüşümler, kaybın firsata dönüşümünün travma sonrası gelişimi sağlayan faktörler olduğunu belirtmiştir. Travma sonrası büyüme düzeyi yüksek olan bireyler, karşı karşıya kaldıkları yaşam problemlerinin üstesinden gelebilecek gücü kendilerinde hissetmekte ve baş etme becerilerine sahip oldukları için travmanın olumlu yönlerine odaklanarak travma ile daha rahat baş edebilmektedir (Özçetin-Üzar ve Hiçdurmaz, 2017). Dolayısıyla travma sonrası büyümenin bireylerin baş etme becerilerini geliştirerek COVID pandemisinin olumsuz etkilerini azaltma da katalizör görevi görebileceği düşünülmektedir.

Tedeschi ve Calhoun (2004) yapmış oldukları çalışmada, travma sonrası büyümenin tutarlı olma algısı, psikolojik sağlamlık ve iyimserlik ile ilişkili olduğunu ortaya koymuşlardır. Travma sonrası büyüme ile ilişkili olan iyimserlik kavramı, iyi şeylerin kötü şeylerden daha sık meydana geldiğine dair kendi kendine bildirilen genel bir beklentidir (Zoellner ve Maercker, 2006). İyimserlik ve travma arasındaki ilişkiler, çeşitli güçlüklerle karşılaşan birey gruplarında incelenmiştir. Benight ve Bandura (2004) yapmış oldukları çalışmalarında, travma ile baş edebileceklerini algılayan bireylerin hayata daha olumlu baktıklarını ve çevrelerini kontrol edebildikleri için de hayatlarında iyi şeylerin olmasını beklediklerini bulgulamışlardır. Ayrıca, Broekhof ve ark. (2015) bir kişinin iyimserlik eğiliminin belirli çevresel faktörlere göre atfedilebileceğine dair kanıtlar olduğunu ve yaptıkları çalışmalarında, iyimserliğin çocukluk çağı travmalarının tüm alt tipleri ile ters yönde ilişkili olduğunu bulmuşlardır. Buna ilave olarak, olumlu ruh hali ile iyimserlik arasında ilişki olduğunu, iyimserliğin olumlu ruh hali, moral yüksekliği, sebat, olumsuz travmatik semptomların üstesinden gelme ve etkili problem çözmeyi sağladığını belirtmişlerdir. İyimser olan insanlar genellikle başlarına gelen olayların nedenlerini açıklar ve bu açıklamaları sıkıntıdan büyümeye doğru bir basamak olarak kullanırlar (Fredrickson, 2001; Peterson ve Steen, 2012).

Yaşamda iyi sonuçlar bekleme eğilimi olarak tanımlanan iyimserlik (Urcuyo, Boyers, Carver ve Antoni, 2005), içinde yaşanılan durum ve koşullardan bağımsız olarak, 
S. B. Çelik, N. D. Çabuker, M. V. Batık ve H. Epli/ Pamukkale Üniversitesi Eğitim Fakültesi Dergisi, 55, 180-202, 2022183 bireyin yaşamında olumsuz sonuçlar yerine olumlu durumlarla karşılaşma beklentisinde olma durumudur. İyimserliğin, olumlu duygular, moral, akademik başarı, etkili problem çözme ve sağlıklı uzun yaşam için kritik öneme sahip olduğu ve travmalardan kurtulmak için önemli bir yol olarak değerlendirildiği belirtilmektedir. Yaşama ayak uydurma özelliği olarak görülen iyimserliğin aksine kötümserlik ise, ruhsal bir yetersizlik olarak değerlendirilmektedir (Daco, 1989). Kötümserliğin, sosyal yetersizlik, edilgenlik, hastalık, başarısızlık ve depresyonun bir yansıması olduğu kabul edilmiştir (Peterson, 2000; Seligman, 1998). Zorluklara ve engellemelere rağmen hayatta her şeyin yolunda gideceğine dair güçlü bir beklenti içerisinde olan iyimser bireyler (Goleman, 2000), olumsuz düşüncelerini engelleyebilir ve olumsuz düşünceleri mantıklı bir şekilde gözden geçirebilirler. Aynı zamanda kendilerini rahat ve huzurlu hissederek geleceğe güvenle bakarlar. İyimserlik eğilimi ise; bilişsel bir süreç olup sonradan edinilebilir (Scheier ve Carver, 1985). İki tür iyimserlik vardır: İlki kişilik özelliği olarak (dispositional optimism) ele alınan iyimserlik; ikincisi ise, durumsal iyimserliktir (situational optimism). Kişilik özelliği olan iyimserliğe sahip olan bireyler, yaşam olaylarını değerlendirirken olumlu olaylara daha çok odaklanır. Durumsal iyimserler ise, iyi şeylerin olacağını beklemektedirler (Seligman, 1998). Birey hayatı boyunca sayısız olay, olgu ve kişilerle etkileşime girmektedir. Etkileşime girdiği yaşam olayları ve kişiler bireyin yaşamına olumlu ya da olumsuz katkılarda bulunmaktadır. İyimserlik, bireylerin travma ile baş etmelerinde önemli etkiye sahiptir. Nolen-Hoeksema (2000) yakınını kaybetmiş iyimserlerin acı ile başa çıkabilmek için kaybı pozitif açıdan yeniden değerlendirme, sosyal destek alarak sorunu çözme eğiliminde olduklarını belirtmiştir. İyimser bireyler, travmayı hayatlarındaki öncelikleri belirlemek için bir uyanma çağrısı olarak yorumlamaktadırlar. Yaşamın kırılganlığının farkına varıp, daha çok şimdiki zamanda yaşarlar. Başkalarına karşı daha hoşgörü olup kendilerinde olduğunu bilmedikleri güçlü yönlerinin farkına varırlar (Carr, 2016). COVID pandemisinin yarattığı belirsizlik nedeniyle bu duruma yönelik koruyucu işleve sahip değişkenlerin ele alınmasının birey ve toplum sağlı̆̆ açısından önemli olacağ düşünülmektedir.

Alanyazında yer alan araştırma sonuçlarında ortak tema, insanlarda travmatik olaylar yaşadıktan sonra ortaya çıkan büyümedir. Bu ise, iyimserliğin stresli deneyimler karşısında yaşama ilişkin anlam oluşturmaya ve olumlu büyümeye yönelik destekleyici bir işlev görebileceğini düşündürmektedir. Dolayısıyla bu araştırmada, öğretmen adaylarının COVID salgını sürecinde deneyimledikleri olumsuz yaşantılardan iyimserlik yoluyla sağladıkları 
184 S. B. Çelik, N. D. Çabuker, M. V. Batık ve H. Epli/ Pamukkale Üniversitesi Eğitim Fakültesi Dergisi, 55, 180-202, 2022 olumlu duygular ile travma sonrası büyümeyi ne oranda açıkladığını belirlemek amaçlanmıştır. Araştırma sonucunda elde edilen bulguların iyimserliğin özellikle çok geniş kitleleri etkileyen bir travma olan COVID pandemisinin psikolojik etkilerinin düzenlenmesi sürecinde travma sonrası büyüme için başa çıkma stratejisi olarak ele alınmasına katkı sunacağı düşünülmektedir. Tüm bu bilgiler 1şığında bu araştırmada cevap aranan sorular şunlardır:

1. Olayın (COVID salgını) etkisi, iyimserlik ve travma sonrası büyüme arasında anlamlı düzeyde ilişki var mıdır?

2. Olayın (COVID salgını) etkisi ve iyimserlik, travma sonrası büyümeyi anlamlı olarak yordamakta midir?

3. Olayın (COVID salgını) etkisi, travma sonrası büyüme ve iyimserlik; cinsiyete, online psikolojik destek alma ve maneviyata yönelme durumlarına göre anlamlı ölçüde farklılık göstermekte midir?

\section{Yöntem}

$\mathrm{Bu}$ çalışma, Ondokuz Mayıs Üniversitesinin Eğitim Fakültesinde 2020 yılında eğitim görmekte olan öğretmen adayları ile gerçekleştirilmiştir. İlişkisel tarama türünde olan bu araştırmada, COVID salgınının etkisi, travma sonrası büyüme ve iyimserlik arasındaki ilişkiler incelenmiştir. Araştırma, Ondokuz Mayıs Üniversitesi Sosyal ve Beşerî Bilimler Etik Kurulunun 29/052020 tarihli 2020/307 sayılı kararı ile alınan izinle yürütülmüştür.

\section{Çalışma Grubu}

Araştırmanın çalışma grubunu, Ondokuz Mayıs Üniversitesi'nde öğrenim gören ve uygun örnekleme yöntemiyle ulaşılan 801 öğretmen adayı oluşturmuştur. Eğitim Fakültesi’nde öğrenim gören tüm öğrencilere uzaktan eğitim sürecinde çevrimiçi olarak anket linki gönderilmiş ve gönüllü olan öğretmen adayları araştırmaya katılmıştır.

Araştırmaya katılan öğretmen adaylarının \%74.5'i kadın (n=597) ve \%25.5'i erkektir (n=204). Araştırmaya katılanların \%52.2'si ilde, \%33'ü ilçede ve \%14.9'u köyde yaşamaktadır. Altı öğretmen adayının COVID tanısı aldığı, \%15.1'inin ise bir yakınının COVID tanısı aldığı görülmüştür. Katılımcıların yaşları 17 ile 27 arasında ve yaş ortalaması 21.79'dur. 
S. B. Çelik, N. D. Çabuker, M. V. Batık ve H. Epli/ Pamukkale Üniversitesi Eğitim Fakültesi Dergisi, 55, 180-202, 2022185

\section{Veri Toplama Araçları}

Araştırmada veriler, “Olayların Etkisi Ölçeği, İyimserlik Ölçeği, Travma Sonrası Büyüme Envanteri ve Bilgi Toplama Formu” aracılığıyla toplanmıştır.

\section{Olayların etkisi ölçeği (OË̈)}

Ölçek, Horowitz, Wilner ve Alvarez (1979) tarafından geliştirilmiş; Weiss ve Marmar (1997) ile Creamer, Bell ve Failla (2003) tarafından revize edilmiştir. Revize edilen form Türkçe'ye Çorapçıŏlu, Yargıç, Geyran ve Kocabaşoğlu (2006) tarafından uyarlanmış olup, stresli ve travmatik bir yaşantı ardından yaşanan zorlukların bireylerin hayatını ne ölçüde zorlaştırdığını ölçmeyi amaçlamaktadır. 5'li Likert tipi puanlamaya sahip olan ölçekten alınabilecek en düşük puan 0 , en yüksek $88^{\prime}$ 'dir. Ölçekten yüksek puan alınması olaydan etkilenme miktarının da yüksek olduğuna işaret etmektedir. Ölçeğin Cronbach Alfa iç tutarlılık katsayısı .94'tür (Çorapçığlu vd., 2006). Mevcut çalışmada ise Cronbach alpha iç tutarlılık katsayısı .91 olarak hesaplanmıştır.

İyimserlik ölçeği (ïÖ)

Balcı ve Yılmaz (2002) tarafından Türk kültüründe geliştirilmiş olan ölçek, bireylerin iyimserlik düzeylerini ölçmektedir. Ölçek tek boyuttan oluşmakta ve 24 madde içermektedir. 4'lü Likert tipi bir ölçekten alınabilecek en düşük puan 24, en yüksek puan ise 96'dır. Ölçekten yüksek puan alınması, iyimserlik düzeyinin de yüksek olduğunu belirtmektedir. Ölçeğin Cronbach Alfa iç tutarlılık katsayısı .96 ve test- tekrar test korelasyon katsayısı ise .61'dir (Balcı ve Yılmaz, 2002). Mevcut çalışmada ise Cronbach alpha iç tutarlılık katsayısı .93 olarak hesaplanmıştır.

\section{Travma sonrası büyüme envanteri (TSBE)}

Tedeschi ve Calhoun (1996) tarafından geliştirilen ölçek, Türkçe’ye Kağan, Güleç, Boysan ve Çavuş (2012) tarafından uyarlanmıştır. Bireylerin yaşamlarında önemli yer tutan travmatik yaşam olaylarının, hayatlarında ne ölçüde olumlu değişikliklere sebep olduğunu belirlemek amacıyla kullanılmaktadır. 6'lı Likert tipi ölçekten alınabilecek en düşük puan 0 , en yüksek 105 'tir. Ölçekten yüksek puan alınması travma sonrası büyümenin yüksek olduğuna işaret etmektedir. Ölçeğin Cronbach Alfa iç tutarlılık katsayısı .92 olarak bulunmuştur. Test-tekrar test korelasyon katsayısı ise .83'tür (Kağan vd., 2012). Mevcut çalışmada ise Cronbach alpha iç tutarlılık katsayısı .95 olarak hesaplanmıştır. 
186 S. B. Çelik, N. D. Çabuker, M. V. Batık ve H. Epli/ Pamukkale Üniversitesi Eğitim Fakültesi Dergisi, 55, 180-202, 2022 Bilgi toplama formu

Araştırmacılar tarafından hazırlanan formda katılımcıların yaş, cinsiyet, bölüm, yaşam yeri, COVID tanısı alma, uzaktan eğitime katılma gibi bilgileri almaya yönelik sorular bulunmaktadir.

\section{Verilerin Toplanması}

İlk olarak Sosyal ve Beşerî Bilimler Etik Kurulu'ndan gerekli izinler alınmıştır. Google form ile hazırlanan ölçme araçları linki, uzaktan eğitime katılan öğretmen adaylarına ulaştırılmıştır. Araştırmaya katılmaya gönüllü olan öğretmen adayları anketi çevrimiçi olarak doldurmuşlardır. Anket formu yaklaşık 15 dakikada cevaplanmaktadır.

\section{Verilerin Analizi}

İlk olarak Mahalanobis uzaklığı hesaplanarak uç değerlere sahip veriler belirlenmiş; uç değerlere sahip üç verinin olduğu belirlenmiş; bu veriler çıkartılarak 801 veri üzerinde analizler gerçekleştirilmiştir. Çok değişkenli analizlerin yapılabilmesi için normallik, doğrusallık ve eşvaryanslılık varsayımları test edilmiştir. Basıklık ve çarpıklık değerleri sırasıyla, olayın etkisi için .17 ve .62; travma sonrası büyüme için -.76 ve -.01; iyimserlik için .03 ve -.65 olarak hesaplanmıştır. İkili değişken kombinasyonlarının saçılma diyagramları incelenmiş; saçılmaların hepsinin elips ve elipse yakın şekillerde olduğu görülmüştür. Değişkenlere ilişkin elde edilen artık grafikleri incelendiğinde, değerlerin doğrusal bir eksen etrafında toplandığ görülmüştür. Box's M testi sonucunda varyansların homojenliği varsayımının karşılandığı görülmüştür (Box's M=43.73, p=.058). Tüm bu veriler doğrultusunda çok değişkenli analizlerin yapılabilmesi için gerekli tüm varsayımların karşılandığı belirlenmiştir. Korelasyon analizi, Hiyerarşik regresyon analizi, Tek Yönlü MANOVA ve İki Yönlü MANOVA yapılmıştır.

\section{Bulgular}

Olayın (COVID salgını) etkisi, travma sonrası büyüme ve iyimserlik puan ortalamaları, standart sapma değerleri ve korelasyon katsayıları Tablo 1'de verilmiştir. Olayın etkisi ile travma sonrası büyüme arasında pozitif yönde zayıf ilişki $(r=.09, \mathrm{p}<.01)$; olayın etkisi ile iyimserlik arasında negatif yönde orta düzeyde ilişki ( $\mathrm{r}=-.31, \mathrm{p}<.01)$; travma sonrası büyüme ile iyimserlik arasında ise pozitif yönde orta düzeyde ilişki $(r=.49, p<.01)$ bulunmaktadır. 
S. B. Çelik, N. D. Çabuker, M. V. Batık ve H. Epli/ Pamukkale Üniversitesi Eğitim Fakültesi Dergisi, 55, 180-202, 2022187 Tablo 1. Korelasyon katsayıları, ortalama ve standart sapma değerleri

\begin{tabular}{lccccc}
\hline Değişkenler & Ort. & SS & 1 & 2 & 3 \\
\hline Olayın etkisi (1) & 31.71 & 16.62 & - & $-.31^{*}$ & $.09^{*}$ \\
İyimserlik (2) & 49.89 & 23.90 & - & - & $.49^{*}$ \\
Travma sonrası büyüme (3) & 70.96 & 14.65 & - & - & \\
\hline
\end{tabular}

$* p<.01$

\section{Regresyon Analizi}

Öğretmen adaylarında travma sonrası büyümeyi yordayan değişkenleri tespit etmek amacıyla hiyerarşik regresyon analizi yapılmıştır (Tablo 2). Buna göre iyimserlik $(\mathrm{t}=18.62$, $\mathrm{p}<.001)$ ve olayın etkisi $(\mathrm{t}=8.69, \mathrm{p}<.001)$ değişkenlerinin travma sonrası büyümeyi anlamlı olarak yordadığı belirlenmiştir. İyimserlik, travma sonrası büyümenin $\% 24$ 'ünü $\left(\mathrm{R}^{2}=.24\right.$, $\left.\mathrm{F}_{\text {Değisim }}(1,799)=257.08, \mathrm{p}=.000\right)$ yordamaktadır. Ayrıca olayın etkisi ise toplam varyansa $\% 6$ oranında $\left(\Delta \mathrm{R}^{2}=.06, \mathrm{~F}_{\text {Değişim }}(1,798)=75.64, \mathrm{p}=.000\right)$ katkıda bulunmaktadır. Değişkenlere ilişkin $\beta$ değerlerine göre, travma sonrası büyümeyi birinci sırada "iyimserlik", ikinci sırada ise "olayın etkisi" anlamlı olarak yordamaktadır. Diğer bir ifadeyle travma sonrası büyümenin \%24'ünü iyimserlik; \%6'sını olayın etkisi açıklamakta; bu iki değişken öğretmen adaylarında travma sonrası büyümenin \%31'ini yordamaktadır $\left(\mathrm{R}^{2}=.31, \mathrm{~F}_{(2}\right.$, 798) $=178.37, \mathrm{p}=.000)$. 


\begin{tabular}{|c|c|c|c|c|c|c|c|c|}
\hline & $\begin{array}{l}\text { Yordayıcı } \\
\text { değișken }\end{array}$ & Reg. Kat. & St. hata & $\boldsymbol{\beta}$ & $\mathbf{t}$ & $\mathbf{R}$ & $\mathbf{R}^{2}$ & $\mathbf{F}$ \\
\hline \multirow{2}{*}{1} & Sabit & -7.21 & 3.63 & - & $-1.98 *$ & \multirow{2}{*}{.49} & \multirow{2}{*}{.24} & \multirow{2}{*}{257.08} \\
\hline & İyimserlik & .80 & .05 & .49 & $16.03 * *$ & & & \\
\hline \multirow{3}{*}{2} & Sabit & -28.98 & 4.28 & - & $-6.76^{* *}$ & \multirow{3}{*}{.55} & \multirow{3}{*}{.31} & \multirow{3}{*}{178.37} \\
\hline & İyimserlik & .94 & .05 & .57 & $18.62 * *$ & & & \\
\hline & Olayın etkisi & .39 & .04 & .27 & $8.69 * *$ & & & \\
\hline \multicolumn{9}{|c|}{$\mathrm{R}=.56, \mathrm{R}^{2}=.31, \mathrm{~F}_{(2,798)}=178.37, p=.000$} \\
\hline \multicolumn{9}{|c|}{$* p<.05, * * p<.000$} \\
\hline
\end{tabular}

\section{Çok Değişkenli Varyans Analizi}

Olayın (COVID salgını) etkisi, travma sonrası büyüme ve iyimserliğin cinsiyete göre farklılaşma durumunu belirlemek için yapılan Tek Yönlü MANOVA sonucuna göre (Tablo 3), olayın etkisi, travma sonrası büyüme ve iyimserlik puanları üzerinde cinsiyetin temel etkisi anlamlı bulunmuştur $\left(\lambda=.97, \mathrm{~F}_{(3,797)}=6.48, \mathrm{p}<.001\right)$. Öğretmen adaylarının olayın (COVID salgını) etkisi puan ortalamaları kadın ve erkek öğrenciler arasında anlamlı düzeyde farkl11ık göstermektedir $\left[\mathrm{F}_{(1,799)}=8.94, \mathrm{p}<.01\right]$. Buna göre kadınların COVID salgınından erkeklere göre anlamlı ölçüde daha çok etkilendiği belirtilebilir. Öğretmen adaylarının travma sonrası büyüme puan ortalamalarının da cinsiyete göre anlamlı ölçüde farklılaştı̆̆ belirlenmiştir $\left.\left[\mathrm{F}_{(1,} 799\right)=12.03, \mathrm{p}<.01\right]$. Kadınların travma sonrası büyüme düzeyleri erkeklere göre anlamlı ölçüde daha yüksek olmakla birlikte, kısmî etakare değerleri $\left(\eta^{2}=.024\right)$ bu etkinin çok düşük olduğunu göstermektedir. Öğretmen adaylarının iyimserlik düzeyleri ise cinsiyete göre anlamlı ölçüde farklılaşmamaktadır $\left[\mathrm{F}_{(1,799)}=.97\right.$, $\mathrm{p}>.05]$. 
S. B. Çelik, N. D. Çabuker, M. V. Batık ve H. Epli/ Pamukkale Üniversitesi Eğitim Fakültesi Dergisi, 55, 180-202, 2022189 Tablo 3. Tek yönlü MANOVA sonuçları

\begin{tabular}{lccccccc}
\hline Değişken & Kaynak & $\mathrm{n}$ & Ortalama & $\mathrm{Ss}$ & $\mathrm{Sd}$ & $\mathrm{F}$ & $\mathrm{K}$ ısmi $\eta^{2}$ \\
\hline Olayın etkisi & Kadın & 597 & 32.74 & 16.63 & 1 & $8.94 *$ & .011 \\
& Erkek & 204 & 28.73 & 16.24 & & & \\
İyimserlik & Kadın & 597 & 71.26 & 14.56 & 1 & .97 & .001 \\
Travma sonrası & Krkek & 204 & 70.09 & 14.91 & & & \\
büyüme & Erkek & 204 & 44.92 & 23.89 & 1 & $12.03 * *$ & .015 \\
\hline (Wilk’s Lambda $(\lambda)=.97$, Kısmi $\left.\eta^{2}=.024, \mathrm{~F}_{(3,797)}=6.48, \mathrm{p}=.000\right)$ & & & \\
$* p<.01, * * p<.001$ & & & & & & \\
\hline
\end{tabular}

Olayın (COVID salgını) etkisi, travma sonrası büyüme ve iyimserliğin online psikolojik destek alma ve maneviyata yönelme durumlarına göre farklılaşma durumunu belirlemek için yapılan İki Yönlü MANOVA sonuçlarına göre (Tablo 4), online psikolojik destek alma ve maneviyata yönelme durumlarının; olayın etkisi, travma sonrası büyüme ve iyimserlik üzerinde ortak etkisinin olmadığ $795)=1.89, \mathrm{p}>.05)$.

Online psikolojik destek alma ve maneviyata yönelmenin olaydan (COVID salgını) etkilenme üzerindeki ortak etkisinin anlamlı olduğu $\left(\mathrm{F}_{(1,797)}=4.13, \mathrm{p}<.05\right)$, kısmî etakare değerlerine göre $\left(\eta^{2}=.007\right)$ ise bu etkinin çok küçük olduğu belirlenmiştir. Online psikolojik destek alan öğretmen adaylarından maneviyata yönelenlerin olaydan etkilenme düzeyleri maneviyata yönelmeyenlere göre daha düşüktür. Online psikolojik destek almayan öğretmen adaylarından maneviyata yönelen ve yönelmeyenlerin olaydan etkilenme düzeyleri ise farklılık göstermemektedir. Öğretmen adaylarının olaydan (COVID salgınından) etkilenme düzeyleri, online psikolojik destek alma $\left[\mathrm{F}_{(1,797)}=37.71, \mathrm{p}<.001\right]$ ve maneviyata yönelme $\left[\mathrm{F}_{(1,797)}=4.26, \mathrm{p}<.05\right]$ durumlarına göre anlamlı ölçüde değişmektedir. Bonferroni testi sonuçlarına göre ise, online psikolojik destek alan öğretmen adaylarının olayın etkisi puan ortalamaları $(\mathrm{M}=46.67, \mathrm{SD}=2.5)$, psikolojik destek almayanlara göre $(\mathrm{M}=30.86$, $\mathrm{SD}=.59$ ) anlamlı ölçüde daha yüksektir. Maneviyata yönelen öğretmen adaylarının olayın etkisi puan ortalamaları $(\mathrm{M}=36.11, \mathrm{SD}=1.86)$, maneviyata yönelmeyenlere göre $(\mathrm{M}=41.43$, $\mathrm{SD}=1.77$ ) anlamlı ölçüde daha düşüktür. 
190 S. B. Çelik, N. D. Çabuker, M. V. Batık ve H. Epli/ Pamukkale Üniversitesi Eğitim Fakültesi Dergisi, 55, 180-202, 2022 Tablo 4. İki yönlü MANOVA sonuçları

\begin{tabular}{|c|c|c|c|c|c|c|}
\hline $\begin{array}{l}\text { Bağımsız } \\
\text { değişken }\end{array}$ & Kaynak & $\begin{array}{l}\text { Kareler } \\
\text { Top. }\end{array}$ & $\mathrm{Sd}$ & $\begin{array}{l}\text { Kareler } \\
\text { Ort. }\end{array}$ & $\mathrm{F}$ & $\begin{array}{l}\text { Kismi } \\
\eta^{2}\end{array}$ \\
\hline \multirow{5}{*}{ Olayın etkisi } & O.P.D. ${ }^{(1)}$ & 9914.84 & 1 & 9914.84 & $37.71 * *$ & .045 \\
\hline & M.Y. ${ }^{(2)}$ & 1121.76 & 1 & 1121.76 & $4.26 *$ & .005 \\
\hline & O.P.D.* M.Y. & 1087.29 & 1 & 1087.29 & $4.13^{*}$ & .005 \\
\hline & Hata & 209513.1 & 797 & 262.87 & & \\
\hline & Toplam & 1026575.0 & 801 & & & \\
\hline \multirow{5}{*}{ İyimserlik } & O.P.D. & 3031.32 & 1 & 3031.32 & $15.05^{* *}$ & .019 \\
\hline & M.Y. & 1143.64 & 1 & 1143.64 & $5.67 *$ & .007 \\
\hline & O.P.D.* M.Y. & 72.47 & 1 & 72.47 & .36 & .000 \\
\hline & Hata & 160532.44 & 797 & 201.42 & & \\
\hline & Toplam & 4205383.0 & 801 & & & \\
\hline \multirow{5}{*}{$\begin{array}{l}\text { Travma sonras1 } \\
\text { büyüme }\end{array}$} & O.P.D. & 435.49 & 1 & 435.49 & .89 & .001 \\
\hline & M.Y. & 9962.81 & 1 & 9962.81 & $20.5^{* *}$ & .025 \\
\hline & O.P.D.* M.Y. & 414.17 & 1 & 414.17 & .85 & .001 \\
\hline & Hata & 387274.89 & 797 & 485.91 & & \\
\hline & Toplam & 2451103.0 & 801 & & & \\
\hline \multicolumn{7}{|c|}{$\left(\lambda=.99\right.$, K1smi $\left.\eta^{2}=.007, \mathrm{~F}_{(3,795)}=1.89, \mathrm{p}=.12\right)$} \\
\hline$* p<.05$ & P & De & & ane & önelme & \\
\hline
\end{tabular}

Online psikolojik destek alma ve maneviyata yönelmenin travma sonrası büyüme üzerindeki ortak etkisinin anlamlı olmadığı görünmektedir $\left(\mathrm{F}_{(1,797)}=.85, \mathrm{p}>.05, \eta^{2}=.001\right)$. Maneviyata yönelen öğretmen adayların travma sonrası büyüme düzeyleri online psikolojik destek alan ve almayanlar arasında farklılık göstermemektedir. Online psikolojik destek alsa da almasa da maneviyata yönelmiş öğretmen adaylarının travma sonrası büyüme puanları diğer gruplardan daha yüksektir. Online psikolojik destek almayan öğretmen adaylarından maneviyata yönelmeyenlerin ise travma sonrası büyüme düzeyleri daha düşüktür. Online psikolojik destek alma ile maneviyata yönelme durumunun travma sonrası büyümeye ortak etkisi olmamasına karşın, maneviyata yönelme daha belirleyeci bir değişken olarak göze çarpmaktadır. Öğretmen adaylarının travma sonrası büyüme düzeyleri, online psikolojik destek alma durumuna göre anlamlı ölçüde farklılık göstermezken $\left[\mathrm{F}_{(1,797)}=.89, \mathrm{p}>.05\right]$; 
S. B. Çelik, N. D. Çabuker, M. V. Batık ve H. Epli/ Pamukkale Üniversitesi Eğitim Fakültesi Dergisi, 55, 180-202, 2022191 maneviyata yönelme durumuna göre anlamlı ölçüde farkl1lık göstermektedir $\left[\mathrm{F}_{(1,797)}=20.5\right.$, $\mathrm{p}<.001]$. Bonferroni testi sonuçlarına göre, maneviyata yönelen öğretmen adaylarının travma sonrası büyüme puan ortalamaları $(\mathrm{M}=60.75, \mathrm{SD}=2.54)$, maneviyata yönelmeyenlere göre $(\mathrm{M}=44.91, \mathrm{SD}=2.41)$ anlamlı ölçüde daha yüksektir.

Online psikolojik destek alma ve maneviyata yönelmenin iyimserlik üzerindeki ortak etkisinin anlamlı olmadığ belirlenmiştir $\left(\mathrm{F}_{(1,797)}=.36, \mathrm{p}>.05, \eta^{2}=.000\right)$. Online psikolojik destek alan ve almayan öğretmen adaylarından maneviyata yönelenlerin iyimserlik düzeyleri maneviyata yönelmeyenlere göre daha yüksektir. Ayrıca maneviyata yönelen öğretmen adaylarından online psikolojik destek alanların iyimserlik düzeyleri online psikolojik destek almayanlara göre daha düşüktür. Online psikolojik destek alma ile maneviyata yönelme durumunun iyimserliğe ortak etkisi olmamasına karşın, online psikolojik destek alma ve maneviyata yönelme değişkenlerinin, birbirinden bağımsız olarak iyimserlik üzerinde etkili olduğu görülmektedir. Öğretmen adaylarının iyimserlik düzeyleri, online psikolojik destek alma $\left[\mathrm{F}_{(1,797)}=15.05, \mathrm{p}<.001\right]$ ve maneviyata yönelme $\left[\mathrm{F}_{(1,797)}=5.67, \mathrm{p}<.05\right]$ durumlarına göre anlamlı ölçüde değişmektedir. Bonferroni testi sonuçlarına göre, online psikolojik destek alan öğretmen adaylarının iyimserlik düzeyleri $(\mathrm{M}=63.19, \mathrm{SD}=2.19)$, psikolojik destek almayanlara göre $(\mathrm{M}=71.93, \mathrm{SD}=.52)$ anlamlı ölçüde daha düşüktür. Maneviyata yönelen öğretmen adaylarının iyimserlik düzeylexri ise $(\mathrm{M}=70.24, \mathrm{SD}=1.63)$, maneviyata yönelmeyenlere göre (M=64.87, $\mathrm{SD}=1.55)$ anlamlı ölçüde daha yüksektir.

Kısacası online psikolojik destek alan öğretmen adaylarının olaydan (COVID salgınından) daha çok etkilenmiş oldukları ve iyimserlik düzeylerinin daha düşük olduğu söylenebilir. Salgın sürecinde maneviyata yönelen öğretmen adaylarının olaydan etkilenme düzeylerinin daha düşük olduğu; travma sonrası büyüme ve iyimserlik düzeylerinin daha yüksek olduğu belirtilebilir.

\section{Tartışma}

Öğretmen adaylarında, olayın (COVID salgınının) etkisi, travma sonrası büyüme ve iyimserliğin incelendiği bu araştırmada, iyimserlik ve olayın etkisinin, travma sonrası büyümeyi anlamlı olarak yordadığını göstermektedir. Regresyon analizi sonuçlarının etki büyüklükleri dikkate alındığında, olayın etkisi ve iyimserlik travma sonrası büyümeyi yordama gücünün farklılık gösterdiği bulgulanmıştır. Buna göre etki büyüklükleri bakımından ele alındığında; iyimserlik en büyük etkiye sahipken bunu daha sonra olayın etkisi takip etmektedir. Beta değerinin pozitif olması ise, aralarındaki ilişkinin doğrusal yönlü olduğunu göstermektedir. Yani iyimserlik ve olayın etkisi puanları arttıkça, travma 
192 S. B. Çelik, N. D. Çabuker, M. V. Batık ve H. Epli/ Pamukkale Üniversitesi Eğitim Fakültesi Dergisi, 55, 180-202, 2022 sonrası büyüme puanlarının da artış gösterdiğini ortaya koymaktadır. Bu sonucun elde edilmesinde yaşanan COVID salgınının doğal yollarla oluşan ve geniş bir zaman dilimine yayılan travmatik yaşantının olmasının yanı sıra tüm dünya üzerindeki insanların yaşamı için tehdit oluşturuyor olması da etkili olmuş olabilir. Yani ani gelişen travmatik olayların bilerek ve amaçlı yapılan travmatik olaylardan daha akut bir etkiye sahip olması nedeniyle yaşanan olayın etkisinin şiddetinin ikinci planda kalmasına neden olmuş olabilir. Gerek geçmiş gerekse mevcut araştırma sonuçları, bireyin yaşamını tehdit eden ve kontrol edemediği bir süreç olarak yaşanan ve kitlesel bir travma olan COVID salgınının sonuçlarının olumluya çevrilmesi sürecinde, iyimserliğin bir başa çıkma stratejisi olarak ele alınabileceğini ve iyimserliğin travma sonrası büyümenin gelişimi sürecinde etkili olabileceğini ortaya koymaktadır.

Alan yazında travma sonrası büyüme ve iyimserlik ile ilgili bu çalışmanın bulgusuna paralellik gösteren çok sayıda çalışma bulunmaktadır (Bozo, Gündoğdu ve BüyükaşıkÇolak, 2009; Britton, LaLonde, Oshio ve Taku, 2019, Helgeson, Reynolds ve Tomich, 2006; Kraman ve Tarım, 2018; Maercker, 2010; Prati ve Pietrantonu, 2009). Benzer olarak Tedeschi ve Calhoun (2004), iyimserlik ile travma sonrası büyüme puanları arasında pozitif yönde bir ilişki buldukları araştırmalarında; iyimserlik ve travma sonrası büyüme kavramlarının her ikisinin de bilişsel süreçler üzerindeki etkisine vurgu yapmışlardır. Yani iyimser bireylerin, dikkatlerini başa çıkmada önemli rol oynayan kaynaklarına odaklayabileceklerini ve kontrol edilemeyen ya da çözülemeyen sorunlardan uzaklaşabileceklerini bildirmişlerdir. Yine benzer olarak doğal afetten etkilenen bir popülasyonda psikolojik iyi oluş ve travma sonrası büyüme ile ilişkisinin ele alındığı başka bir çalışmada da; iyimserliğin afetin yarattığ 1 etkileri minimalize etmek için önemli bir işleve sahip olduğu görülmüştür (Garcia Martinez, Reyes ve Solar, 2014). Acquaye (2016) Liberyalı mültecilerde iyimserlik, travma sonrası büyüme ve dini bağlılık arasındaki ilişkiyi araştırdığı çalışmasında, savaşla ilgili olayların etkisi ile travma sonrası stres bozukluğu arasında anlamlı bir ilişki olduğunu ortaya koymuştur. Benzer olarak Zoellner, Rabe, Karl ve Maercker (2008), yaşanan travmanın şiddetinin ve iyimserliğin travma sonrası büyüme üzerindeki etkisini araştırdıkları çalışmalarında, travma sonrası stres bozukluğunun şiddeti ve iyimserlik arasında farklı etkileşimlerin etkileri ile travma sonrası büyümenin, travma sonrası stres bozukluğunun şiddetinin hafifletici rolünü ortaya koymuştur.

Pandemi sürecinde bireylerin iyimserlik düzeyleri ile ilgili farklı değişkenler kullanılarak yapılan çalışmalara da rastlanmıştır. Çelebi, Kaya ve Yılmaz (2021) Covid 
S. B. Çelik, N. D. Çabuker, M. V. Batık ve H. Epli/ Pamukkale Üniversitesi Eğitim Fakültesi Dergisi, 55, 180-202, 2022193 pandemisinin etkilerinin farklı alanlarda farklı boyutlarda hissedildiğini ve bu süreçte bireylerde temel duygulardan birinin kaygı olduğunu düşündüklerini belirtmişlerdir. Çalışmada; mizahla başa çıkma, sağlık anksiyetesi ve iyimserlik arasındaki ilişkiyi belirlemek ve mizahla başa çıkma ile sağlık anksiyetesi arasındaki ilişkide iyimserliğin aracı rolünü keşfetmeyi amaçlanmıştır. Aracılık analizleri sonucunda mizahla başa çıkma ile sağlık anksiyetesi arasındaki ilişkide iyimserliğin kısmi aracı rolü olduğu bulgulanmıştır. Tongar, Ülküer, Geçer, Yıldırım, ve Akgül, (2021), 3-6 yaş arasında çocukları olan annelerinin COVID pandemisi sürecinde iyimserlik seviyesini etkileyen faktörleri incelenmişlerdir. Annelerin iyimserlik düzeylerini; eğitim durumu, yaş, gelir durumu, çocuk sayısı ve çalışma gibi değişkenlerin etkilediği, fakat medeni durumun etkilemediği, iyimserlik düzeylerinin evlilik doyumu ve mutluluk düzeyinin artmasına bağlı olarak arttığı; sosyal medya kullanımı ve televizyon izleme süresinin artmasına bağlı olarak da azaldığı bulgulanmıştır. Atar, Urgan ve Erdoğan (2020), Covid-19 salgınının etkilerinin hissedildiği ilk üç ayda gerçekleşen iyimserlik, kötümserlik ve yaşam tatmin düzeylerinin belirlenmesinin amaçlandığı çalışmalarında; genel iyimserlik ve yaşam tatmini düzeylerinin genel kötümserlik düzeyinden yüksek olduğunu, kadınların kötümserlik düzeyinin erkeklerin kötümserlik düzeyinden, evli katılımcıların yaşam tatmin düzeyinin bekâr katılımcıların yaşam tatmin düzeyinden, beyaz yakalı çalışan grubun iyimserlik ve yaşam tatmini düzeyinin de diğer katılımcıların iyimserlik ve yaşam tatmin düzeyinden daha yüksek olduğu sonucuna ulaşmışlardır.

Alan yazında mevcut araştırma sonuçlarıyla uyumlu olarak bu araştırma bulguları da; COVID salgını karşısında başa çıkma becerilerini etkin bir biçimde kullanan bireylerin bu süreçten güçlenerek çıktıklarını ortaya koymaktadır. Diğer bir deyişle, bu süreci olumlu yönleri ile görmeye çalışan bireylerin travmanın etkilerini olumluya dönüştürmede daha avantajlı oldukları söylenebilir. İyimserlik yaşamdaki sorunlara nasıl yaklaşılacağını, zorluklarla nasıl baş edileceğini ve travmatik olaylardan nasıl etkilenileceğini belirleme özeliğine sahiptir. İyimserlik gibi kişisel bir özelliğin başa çıkma tepkileri aracılığıyla travma sonrası büyümeyi teşvik ediyor olması, yaşama tutunmaya yönelik duyguları da güçlendiriyor olabilir. Ayrıca iyimser özelliğe sahip olan insanların, kendileri ile ilgili olumlu değişiklikleri fark etmeye ve travma sonrası başarılarını daha çok hissetmeye daha meyilli olabilecekleri söylenebilir. Bu ise travmatik yaşantıların ardından büyüme üzerinde olumlu bir etki yaratmış olabilir. 
194 S. B. Çelik, N. D. Çabuker, M. V. Batık ve H. Epli/ Pamukkale Üniversitesi Eğitim Fakültesi Dergisi, 55, 180-202, 2022 Araştırmanın diğer bir bulgusuna göre, iyimserlik ve travma sonrası büyüme üzerinde cinsiyetin temel etkisi anlamlı bulunmuştur. Kadın öğretmen adaylarının erkeklere göre hem COVID salgınından daha çok etkilendikleri hem de travma sonrası büyüme düzeylerinin daha yüksek olduğu ayrıca iyimserlik düzeylerinin ise cinsiyete göre farklılık göstermediği belirlenmiştir. Araştırmanın bu bulgusu alanyazında yer alan diğer araştırmalarla benzerlik göstermektedir (Jin, Xu ve Liu, 2014; Zwahlen, Hagenbuch, Carley, Jenewein ve Buchi, 2006). Şahne (2018), 28 Haziran 2016 Atatürk Havaalanı'nda yaşanan terör saldırısına maruz kalmış özel güvenlik çalışanlarının, saldırının ardından ortaya çıkan olumsuz ve olumlu psikolojik etkileri incelediği çalışmasında, kadın güvenlik görevlilerinin travma sonrası büyüme puanlarının erkek güvenlik görevlilerine göre daha yüksek olduğu, cinsiyetin travma sonrası büyümeyi pozitif ve orta düzeyde yordadığı sonucuna ulaşmıştır. Mevcut araştırmanın bu bulgusu cinsiyet rolü stereotipleri ile açıklanabilir. Kadın ve erkeklerin aynı stresörlerle farklı şekilde başa çıkmak için yetiştirilmelerinde özellikle cinsiyet rolü sterotipleri oldukça etkilidir. Yani kadınlar stresörlerle baş edebilmek için başkalarından destek arama ya da başkalarına destek sunma konusunda teşvik edilmeleri bu sonuçta etkili olmuş olabilir. Öte yandan, erkeklerin bu süreçte kadınlardan farklı olarak duygusal destek gibi bir baş etme yöntemi kullanmaları ise zayıflıkla ilişkilendirilebilir. $\mathrm{Bu}$ nedenle, erkeklerin doğrudan eyleme dayalı başa çıkma eylemleri toplumsal bir beklentidir. Kadınların ve erkeklerin travmatik yaşantılar sonrasında büyümeyi nasıl sağlayabilecekleri ile ilgili mekanizmalarını anlamak onlara bu süreci olumluya çevirme konusunda destek sağlayacaktır. Bu konuda aracılık rolü üstlenebilecek değişkenlerin de ele alınması yani kadınların ve erkeklerin ayrı ayrı travma sonrası gelişmelerine kaynaklık edecek değişkenlerin tespiti, onların bu sürecin olumsuz etkilerini olumluya çevirmede kullanılabilecek güçlü bir katalizör görevi görecektir.

Araştırma sonucunda, online psikolojik destek alan öğretmen adaylarının olaydan etkilenme düzeylerinin daha yüksek, travma sonrası büyüme ve iyimserlik düzeylerinin daha düşük olduğunun belirlenmesi dikkati çekmiştir. Bu bulgunun psikolojik destek alan öğretmen adaylarının aldıkları psikolojik destekten olumsuz etkilendiği şeklinde yorumlanması oldukça yanıltıcı olacaktır. Bu salgın sürecinden daha çok olumsuz etkilenmiş olan kişilerin daha çok online psikolojik desteğe başvurdukları düşünülmektedir. Nitekim Topkaya (2014), çalışmasında psikolojik sıkıntının artmasının, psikolojik yardım alma niyetini artırdığını ve psikolojik sıkıntı düzeyinin psikolojik yardım alma niyetinde rol oynayan önemli bir değişken olduğu ifade etmektedir. 
S. B. Çelik, N. D. Çabuker, M. V. Batık ve H. Epli/ Pamukkale Üniversitesi Eğitim Fakültesi Dergisi, 55, 180-202, 2022195

Araştırmanın bir diğer önemli sonucuna göre, salgın sürecinde maneviyata yönelen öğretmen adaylarının olaydan etkilenme düzeylerinin daha düşük olduğu; travma sonrası büyüme ve iyimserlik düzeylerinin daha yüksek olduğu görülmüştür. Acquaye (2017) de benzer olarak iyimserlik düzeyi yüksek olan ve dindar olan mültecilerde travma sonrası büyümenin yüksek düzeyde olduğunu göstermiştir. Buxton (2011), dine bağl1lığın, iyimserliğin ve psikososyal müdahalelere katılımın, travma sonrası büyüme düzeyini yükselttiğini göstermiştir. Travma sonrası sosyal destek ve maneviyatın bireylerin travma sonrası büyüme göstermesinde önemli bir unsur olarak değerlendirilmektedir (Arıcı Özcan ve Arslan, 2020; Tedeschi vd., 1998; Y1lmaz, 2014; Yurtsever, 2018). Mevcut araştırma, COVID salgın sürecinde maneviyata yönelmenin koruyucu işlevini ayrıca travma sonrası büyüme üzerindeki olumlu etkisini ortaya koymaktadır. Yine araştırmanın bu bulgusu insanın maddi varlığının devamlılığını sağlamaya yönelik endişesinin bastırılmasında manevi yönünün desteklenmesinin gerekliliğini ortaya koyması bakımından oldukça önemlidir. COVID salgın sürecinin yaşattı̆ğ travma bireylere yaşamın değerini sorgulamalarına ve yaşamın kutsallığını önceleyen yeni değerler yaratmaya gebe kıldığını göstermektedir. Yaşamın devamlılığına yönelik yüksek risk oluşturan bir salgın sürecinde insanlar bir yandan salgının gerçekleri ile yüzleşirken bir yandan da manevi ritüellerle salgın sürecinin olumsuz etkilerinden korunmayı amaçlamaktadırlar. Salgının süresi ve etkileri düşünüldüğünde ölüm korkusunun dini inançlara yönelimi önemli düzeyde arttırabileceğine yönelik de öngörüde bulunulabilir. Yaşamın devamlılığını tehdit eden ve bireylerde ölüm korkusunun yaşanmasına yol açan böyle bir salgın süreci; dini yaşam ritüellerinin bir başa çıkama stratejisi olarak ön plana çıkmasının yanı sıra uzun vadede maddi kazanımların öncelendiği dünya düzeninden doğaya, çevreye ve insani değerlerin öncelendiği bir dünyaya geçiş ile ilgili farkındalığın oluşmasına da yol açabilir.

\section{Sinırlılıklar ve Öneriler}

Araştırmanın en önemli sınırlılığı, araştırma verilerinin kesitsel sonuçlara yer vermesidir, yani boylamsal sonuçlara yer vermemesidir. COVID salgını geniş bir zaman diliminde yaşanan travmatik bir yaşantı olması dolayısıyla, zaman içinde travma sonrası büyüme üzerindeki etkilerini anlamak için boylamsal çalışmalara ihtiyaç vardır. Araştırmanın diğer bir sınırlılığı ise, katılımcıların bu süreçte kayıp yaşayıp yaşamadıkları ile ilgili herhangi bir bilgiye yer verilmemiş olmasıdır. Ayrıca bu araştırma sadece eğitim fakültesinde öğrenim gören öğrenciler ile gerçekleştirilmiştir. Araştırma sonuçlarının genellenebilirliği açısından farklı örneklem grupları ve farklı yaş dönemlerindeki bireylerle de araştırma sonuçlarının 
196 S. B. Çelik, N. D. Çabuker, M. V. Batık ve H. Epli/ Pamukkale Üniversitesi Eğitim Fakültesi Dergisi, 55, 180-202, 2022 tekrar edilmesi önemli olacaktır. Araştırmanın güçlü yönü ise, COVID salgını ile ilgili travmadan etkilenme düzeyi, travma sonrası büyüme ve iyimserliğin bir arada yer aldığı ilk araştırma olması ve COVID travma sürecinin olası etkilerini ortaya koyması açısından da temel olmasidır.

COVID salgınının hem geçmişi hem de geleceği dikkate alındığında, bireylerin sürekli olarak yüksek düzeyde sağlık tehditleri ile karşı karşıya kalmaları, gelecek dönemlerde fiziksel ve ruhsal sağlıklarını tehdit edebilir. Bu nedenle, böylesi uzun vadeli bir travmanın etkileri, travma sonrası büyüme ile iyimserlik arasındaki ilişkinin ortaya koyulduğu araştırmaların yanı sıra psikoeğitim çalışmalarının da etkisinin araştırılmasına ihtiyaç vardır. Çünkü yaşanan travma sonrası gelişim bireylerin bu süreci olumlu ya da olumsuz ele alış biçimleri süreçten etkilenme düzeylerini de etkilemektedir. COVID salgınını karamsar bir şekilde ele almak öğretmen adaylarının çaresizlik yaşamalarına dolayısıyla da mevcut durumla mücadele güçlerini kaybetmelerine neden olabilir. Öte yandan, bu süreci iyimser bir şekilde ele aldıklarında ise mücadele etme gücünü pekiştirmeleri muhtemeldir. Bu çalışma, travmatik olayların, bireylerin olumsuz durumlarda iyimser düşünme becerilerini geliştirmelerine de kaynaklık edebileceğini ortaya koymaktadır. Buradan hareketle alan çalışanlarının, travmatik yaşantılar karşısında sadece olumsuz sonuçlara değil aynı zamanda olumlu değişikliklere de odaklanmaları gerekmektedir. Bu olumlu değişikliklerin, bireylerin söz konusu travmanın etkilerinden daha çabuk kurtulmalarına kaynaklık edeceği ihtimalini dikkate almaları önem taşımaktadır. Bu nedenle, gerek grupla psikolojik danışma gerekse bireysel psikolojik danışma ile etkili müdahale stratejileri geliştirme sürecinde, mevcut araştırma bulgularının katkıda bulunacağı düşünülmektedir. Deneyimlerin başkalarıyla paylaşılması, olumlu bir bakış açısına sahip olma, iyimserlik, sosyal destek kaynaklarını fark etme ve bu kaynakları etkili şekilde kullanabilme gibi becerilerin travma sonrası büyümeyi geliştirmede etkisi düşünüldüğünde; bu becerilerin yer aldığı psikolojik destek programları travma sonrası büyüme sağlamada faydalı olacaktır (Bonanno, Westphal ve Mancini, 2011; Moreno ve Stanton 2013; Tomich, Helgenson ve Nowak Vache, 2005; Yanez vd., 2011). Bu nedenle bireylerin travma sonras1 büyüme ve iyimserlik düzeylerini yükseltmek ve COVID salgın sürecinin olumsuz etkilerini azaltmak adına psikolojik destek programları hazırlanması önerilmektedir. 
S. B. Çelik, N. D. Çabuker, M. V. Batık ve H. Epli/ Pamukkale Üniversitesi Eğitim Fakültesi Dergisi, 55, 180-202, 2022197 Etik Kurul İzin Bilgisi: Bu araştırma, Ondokuz Mayıs Üniversitesi Sosyal ve Beşerî Bilimler Etik Kurulunun 29/052020 tarihli 2020/307 sayll kararl ile alınan izinle yürütülmüştür.

Yazar Çıkar Çatışması Bilgisi: Bu çalışmada herhangi bir potansiyel çıkar çatışması bulunmamaktadır.

Yazar Katkısı: Tüm yazarlar eşit düzeyde katkı sağlamıştır.

\section{Kaynakça}

Acquaye, H.E. (2016). The relationship among post-traumatic growth, religious commitment, and optimism in adult liberian former refugees and internally displaced persons traumatized by war-related events. Electronic Theses and Dissertations, 2004-2019, 5071.

Acquaye, H.E. (2017). PTSD, optimism, religious commitment, and growth as post-trauma trajectories: A structural equation modeling of former refugees. The Professional Counselor. 7,4, 330-348. http://dx.doi.org/10.15241/hea.7.4.330.

Altan, C. (2013). Üniversite öğrencilerinde travma sonrast gelişimi etkileyen faktörlerin incelenmesi. Yayımlanmamış yüksek lisans tezi, Haliç Üniversitesi, İstanbul.

Arıcı Özcan, N., \& Kaya, M. (2019). Travmatik yas sorununda aile dayanıklılı̆̆ programı'nın kadınların travma sonrası stres, yas ve aile dayanıklılı̆̆ı düzeylerine etkisi. Eğitim ve Bilim, 44, 197, 121-138. http://dx.doi.org/10.15390/EB.2018.7663

Arıkan, G. (2007). Prevalence of traumatic events and determinants of posttraumatic growth in university students. Yayımlanmamış yüksek lisans tezi, Ortadoğu Teknik Üniversitesi. Ankara.

Balc1, S., \& Yılmaz, M. (2002). İyimserlik ölçeğinin geçerlilik ve güvenilirlik çalışması. Ondokuz Mayıs Üniversitesi Ĕ̆itim Fakültesi Dergisi, 14, 54-60.

Bellur, Z. (2015). Meme kanseri hastalarında çevresel, bireysel ve olaya dair faktörlerin travma sonrası gelişim ile ilişkisi. Yayımlanmamış yüksek lisans tezi, Mersin Üniversitesi, Mersin. 
198 S. B. Çelik, N. D. Çabuker, M. V. Batık ve H. Epli/ Pamukkale Üniversitesi Eğitim Fakültesi Dergisi, 55, 180-202, 2022 Benight, C.C., \& Bandura, A. (2004). Social cognitive theory of posttraumatic recovery: The role of perceived self-efficacy. Behavior Research and Therapy, 42, 1129-1148. http://dx.doi.org/10.1016/j.brat.2003.08.008

Bonanno, G.,A., Westphal, M., \& Mancini, A.D. (2011) Resilience to loss and potential trauma. Annual Review of Clinical Psychology, 7, 1, 1-25.

Bozo, Ö., Gündoğdu, E., \& Büyükaşık- Çolak, C. (2009). The moderating role of different sources of perceived social support on the dispositional optimism- posttraumatic growth relationship in postoperative breast cancer patients. Journal of Health Psychology. 14, 7, 1009-1020. http://dx.doi.org/10.1177/1359105309342295

Britton, M., LaLonde, L., Oshio, A., \& Taku, K. (2019). Relationships among optimism, pessimism, and posttraumatic growth in the US and Japan: Focusing on varying patterns of perceived stressfulness. Personality and Individual Differences, 151, 1-6. http://dx.doi.org/10.1016/j.paid.2019.109513

Broekhof, R., Rius-Ottenheim, N., Spinhoven, P., van der Mast, R.C., Penninx, B.W., Zitman, F.G., \& Giltay, E.J. (2015). Long-lasting effects of affective disorders and childhood trauma on dispositional optimism. Journal of Affective Disorders, 175, 351-358. http://dx.doi.org/10.1016/j.jad.2015.01.022

Buxton A. (2011). Posttraumatic growth in survivors of breast cancer: The role of dispositional optimism, coping strategies, and psychosocial interventions. Unpublished doctoral thesis, University of Toronto, Toronto.

Carr, A. (2016). Pozitif psikoloji. (Çev. Ü. Şendilek). İstanbul: Kaknüs Yayınları.

Cao, W., Fang, Z., Hou, G., Han, M., Xu, X., Dong, J., et al. (2020). The psychological impact of the COVID epidemic on college students in China. Psychiatry Research 287,112934, 1-5. http://dx.doi.org/10.1016/j.psychres.2020.112934

Creamer, M., Bell, R., \& Failla, S. (2003). Psychometric properties of the impact of event scale-revised. Behaviour research and therapy, 41,12, 1489-1496. http://dx.doi.org 10.1016/j.brat.2003.07.010

Çorapçığlu, A., Yargıç, İ., Geyran, P., \& Kocabaşoğlu, N. (2006). Olayların Etkisi Ölçeği (IES-R) Türkçe versiyonunun geçerlilik ve güvenilirliği. New Symposium Journal, 44,1, 14-22. http://dx.doi.org

Daco, P (1989). Çăgdaş psikolojinin olağanüstü başarıları. İstanbul: İnkılap Kitabevi. 
S. B. Çelik, N. D. Çabuker, M. V. Batık ve H. Epli/ Pamukkale Üniversitesi Eğitim Fakültesi Dergisi, 55, 180-202, 2022199 Ezerbolat, M., \& Özpolat, A. (2016). Travma sonrası büyüme: Travmaya iyi yanından bakmak. Kriz Dergisi, 24,1, 1-10. http://dx.doi.org/10.1501/Kriz_0000000353

Fredrickson, B.L. (2001). The role of positive emotions in positive psychology: The broaden-and-build theory of positive emotions. American Psychologist, 56, 218-226. http://dx.doi.org/10.1080/10615806.2013.784278

Garcia Martinez, F.E., Reyes, A.R., \& Solar, F.C. (2014). Severity of trauma, optimism, posttaraumatic growth and well-being in survivors of a natural disaster. Universitas Psychologica, 13,2, 575-584. http://dx.doi.org/10.11144/Javeriana.UPSY13-2.stop

Goleman, D. (2000). Duygusal Zeka. İstanbul: Varlık Yayınları.

Güven, K. (2010). Marmara depremini yaşayan yetişkinlerin algıladıkları sosyal destek düzeyleri ile travma sonrası gelişim ve depresyon düzeyleri arasındaki ilişkinin incelenmesi. Yayınlanmamış yüksek lisans tezi, Maltepe Üniversitesi, İstanbul.

Haselden, M. (2014). Üniversite öğrencilerinde travma sonrası büyümeyi yordayan çeşitli değişkenlerin Türk ve Amerikan kültürlerinde incelenmesi: Bir model önerisi. Yayımlanmamış doktora tezi, Hacettepe Üniversitesi, Ankara.

Helgeson, V.S., Reynolds, K.A., \& Tomich, P.L. (2006). A meta-analytic review of benefit finding and growth. Journal of Consulting and Clinical Psychology, 74, 5, 797-816. http://dx.doi.org/10.1037/0022-006X.74.5.797

Horowitz, M., Wilner, N., \& Alvarez, W. (1979). Impact of Event Scale: A measure of subjective stress. Psychosomatic Medicine, 41, 3, 209-218. http://dx.doi.org/10.1097/00006842-197905000-00004

Kağan, M., Güleç, M., Boysan, M., \& Çavuş, H. (2012). Hierarchical factor structure of the Turkish version of the Posttraumatic Growth Inventory in a normal population. TAF Preventive Medicine, 11, 5, 617-624. http://dx.doi.org/10.5455/pmb.1-1323620200

Karadağ, E., \& Yücel, C. (2020). Yeni tip Koronavirüs pandemisi döneminde üniversitelerde uzaktan eğitim: Lisans öğrencileri kapsamında bir değerlendirme çalışması. Yükseköğretim Dergisi, $10,2, \quad$ 181-192. http://dx.doi.org/10.2399/yod.20.730688

Karaman, Ö., \& Tarım, B (2018) Travma sonrası büyüme, sosyal problem çözme ve iyimserlik arasındaki ilişkilerin incelenmesi. Dicle Üniversitesi Sosyal Bilimler Enstitüsü Dergisi, 10, 20, 190-198. 
200 S. B. Çelik, N. D. Çabuker, M. V. Batık ve H. Epli/ Pamukkale Üniversitesi Eğitim Fakültesi Dergisi, 55, 180-202, 2022

Knaevelsrud, C., Liedl, A., \& Maercker, A. (2010). Posttraumatic growth, optimism and openness as outcomes of a cognitive-behavioural intervention for posttraumatic stress reactions. Journal of Health Psychology, 15, 7, 1030-1038. http://dx.doi.org/10.1177/1359105309360073

Moreno, P.I., \& Stanton, A.L. (2013). Personal growth during the experience of advanced cancer a systematic review. Cancer Journal, 19,5, 421-430. https://dx.doi.org/ 10.1097/PPO.0b013e3182a5bbe7

Özcetin-Üzar, Y.D., \& Hiçdurmaz, D. (2017). Posttraumatic growth and resilience in cancer experience. Current Approaches to Psychiatry, 9, 4, 2017, 388- 397. https://dx.doi.org/ 10.18863/pgy.290285

Nolen-Hoeksema, S. (2000). The role of rumination in depressive and mixed anxiety/ depressive symtoms. Journal of Abnormal Psyhology, 109, 3, 504-511.

Park, C., \& Fenster, J. (2004). Stress related growth: predictors of occurence and correlates with psychological adjustment. Journal of Social and Clinical Psychology, 23,2, 195-215. https://dx.doi.org/ 10.1521/jscp.23.2.195.31019

Peterson. C. (2000). The future of optimism. American Psychologist, 55, 1, 44-45. https://dx.doi.org/ 10.1037/0003-066X.55.1.44

Peterson, C., \& Steen, T. A. (2012). Optimistic explanatory style. In S. J. Lopez \& C. R. Snyder (Eds.), Oxford handbook of positive psychology (2nd ed., pp. 313-321). New York, NY: Oxford University Press.

Prati, G., \& Pietrantonu, L. (2009). Optimism, social support, and coping strategies as factors contributing to posttraumatic growth: A meta-analysis. Journal of Loss and Trauma, 14, 3, 64-388.

Scheier, M. F., \& Carver, C. S. (1985). Optimism, coping, and health: Assessment and implications of generalized outcome expectancies. Health Psychology, 4,3, 219-247. https://doi.org/10.1037/0278-6133.4.3.219

Seligman, M. E. P (1998). Learned Optimism, Pocked Boks, New York.

Şahne, M. E. (2018). Atatürk havalimanı saldırısından 6 ay sonra personelde görülen travmatik stres belirtileri ve travma sonrası büyüme ile ilişkili faktörler. Yayınlanmamış yüksek lisans tezi, Üsküdar Üniversitesi, İstanbul. 
S. B. Çelik, N. D. Çabuker, M. V. Batık ve H. Epli/ Pamukkale Üniversitesi Eğitim Fakültesi Dergisi, 55, 180-202, 2022201 Tarım, B. (2019). Yas yaşatısında travma sonrası büyüme. Yayımlanmamış yüksek lisans tezi, Ordu Üniversitesi, Ordu.

Tedeschi, R. G., \& Calhoun, L. G. (1996). The Posttraumatic Growth Inventory: Measuring the positive legacy of trauma. Journal of Trauma Stress, 9, 455-471. https://dx.doi.org/ 10.1007/BF02103658

Tedeschi, R. G., Park, C. L., \& Calhoun, L. G. (1998). Posttraumatic Growth: Conceptual Issues. R. G. Tedeschi, C. L. Park, \& L. G. Calhoun içinde, Posttraumatic growth: Positive changes in the aftermath of crisis (s. 1-23). London: Lawrence Erlbaum Associates Publishers.

Tedeschi, R., \& Calhoun, L. (2004). Posttraumatic growth: Conceptual foundations and empirical evidence. Psychological Inquiry, 15,1, 1-18. https://dx.doi.org/ 10.1207/s15327965pli1501_01

Tomich, P.,L, Helgenson, V.,S. \& Nowak Vache, E., J. (2005). Perceived growth and decline following breast cancer: A comparison to age-matched controls 5-years later. Psychooncology, 14, 1018-1029. https://dx.doi.org/ 10.1002/pon.914

Topkaya, N. (2014). Psikolojik yardım alma niyetini yordamada demografik, bireysel ve çevresel faktörler. Türk Psikoloji Dergisi, 29,74, 1-11.

Tongar, K., Ulkuer, N., Geçer, E., Yıldırım, M., \& Akgül, Ö. (2021). Covid-19 Pandemisi sürecinde annelerin iyimserlik seviyesini etkileyen faktörlerin incelenmesi: Türkiye örneği. Dicle Üniversitesi Sosyal Bilimler Enstitüsü Dergisi, 28, 405-418. Retrieved from https://dergipark.org.tr/en/pub/diclesosbed/issue/65582/960368

Urcuyo, K. R., Boyers, A. E., Carver C. S., \& Antoni, M. H. (2005). Finding benefit in breast cancer: Relations with personality, coping, and concurrent well-being. Psychology Health, 20, 175-192. http://dx. doi.org/10.1080/08870440512331317634.

Wagner, B., Knaevelsrud, C., \& Maercker, A. (2007). Post-Traumatic Growth and Optimism as Outcomes of an Internet-Based Intervention for Complicated Grief. Cognitive Behaviour Therapy 156-161. https://dx.doi.org/10.1080/16506070701339713

Weiss, D., \& Marmar, C. (1997). The impact of event scale-revised. Wilson J., \& Keane T. (Eds.). In Assessing psychological trauma and PTSD. New York: Guilford Press. 
202 S. B. Çelik, N. D. Çabuker, M. V. Batık ve H. Epli/ Pamukkale Üniversitesi Ĕ̆itim Fakültesi Dergisi, 55, 180-202, 2022

Yanez, B., R., Stanton, A., L., Hoyt, M., A., Tennen ,H., \& Lechner S. (2011). Understanding perceptions of benefit following adversity: How do distinct assessments of growth relate to coping and adjustment to stressful events? Journal of Social and Clinical Psychology, 30,7, 699-721. https://dx.doi.org/ 10.1521/jscp.2011.30.7.699

Yazıcı Çelebi, G., Kaya, F., \& Yıılmaz, M. (2021). Covid 19 pandemisi sürecinde mizahla başa çıkma ile sağlık anksiyetesi arasındaki ilişki: iyimserliğin aracı rolü. Süleyman Demirel Üniversitesi Sosyal Bilimler Enstitüsü Dergisi, 40, 24-48. Retrieved from https://dergipark.org.tr/en/pub/sbe/issue/62244/887432

Yeşildal, M., \& Reyhanlığlu, E. (2020). Salgın psikolojisi. İstanbul: Destek Yayınları.

Y1lmaz, M. (2014). Growth through traumatic loss: The effect of grief related factors, coping and personality on posttraumatic growth. Unpublished master thesis, Bilgi Üniversitesi, İstanbul.

Yurtsever, A. O. (2018). Akciğer kanseri hastalarında travma sonrast gelişim, tekrarlayıcı düşünme örüntüleri, algllanan sosyal destek ve belirsizliğe karşı tahammülsüzlük belirtileri arasındaki ilişkiler. Yayınlanmamış yüksek lisans tezi, Ege Üniversitesi, İzmir.

Zoellner, T., \& Maercker, A. (2006). Post-traumatic growth in clinical psychology: a critical review and introduction of a two component model. Clinical Psychology Review, 26, 626-653. https://dx.doi.org/ 10.1016/j.cpr.2006.01.008

Zoellner, T., Rabe, S., Karl, A., \& Maercker A. (2008). Posttraumatic growth in accident survivors: openness and optimism as predictors of 1ts constructive or illusory sides. Journal of Clinical Psyhology, 64,3, 245-263. http://dx.doi.org/10.1002/jclp.20441

Zwahlen, D., Hagenbuch, N., Carley, M.I., Jenewein, J., \& Buchi, S. (2010). Posttraumatic growth in cancer patients and partners--effects of role, gender and the dyad on couples' posttraumatic growth experience. Psycho-oncology, 19,1, 12-20. https://dx.doi.org/10.1002/pon.1486 


\title{
The Impact of Event and Optimism as the Predictors of Post-Traumatic Growth
}

\author{
Seher Balcı Çelik ${ }^{*}$ Nurdan Doğru Çabuker ${ }^{* *}$ Meryem Vural Batık $^{* * *}$ Hatice Epli $^{* * * *}$
}

- Received: 15.06.2022 • Accepted: 24.01.2022 • Online First: 24.01 .2022

\begin{abstract}
During the COVID pandemic, online education in universities in Turkey and many countries continued. During this period, it was curious how many preservice teachers were affected by the pandemic, which is considered a traumatic experience. This study aimed to examine the predictive effects of the COVID pandemic and optimism on post-traumatic growth in preservice teachers. The study group consisted of 801 preservice teachers studying at Ondokuz Mayis University who were reached through the convenience sampling method. Impact of Event Scale, The Posttraumatic Growth Inventory, and Optimism Scale were used as data collection tools. Pearson Moments Correlation analysis showed that post-traumatic growth was positively correlated with the impact of event and optimism, while optimism was negatively correlated with the impact of event. According to hierarchical regression analysis results, it was found that optimism and impact of event predicted post-traumatic growth significantly and explained $31 \%$ of post-traumatic growth. According to one-way MANOVA results, it was found that female preservice teachers were significantly more affected by the COVID pandemic when compared with male preservice teachers, and female preservice teachers had significantly higher post-traumatic growth levels than males. According to two-way MANOVA results, it was found that preservice teachers who received online psychological support during the COVID pandemic were more affected by the event, and they had lower optimism levels. It was also found that preservice teachers who turned to spirituality had lower impact of event levels and higher post-traumatic growth and optimism levels.
\end{abstract}

Keywords: COVID, the impact of an event, post-traumatic growth, optimism, preservice teacher.

\section{Cited:}

Balcı Çelik, S., Doğru Çubuker, N., Vural Batık M., \& Epli, H. (2022). The impact of events and optimism as the predictors of post-traumatic growth. Pamukkale University Jornal of Education, 55, 180-202.doi:10.9779.pauefd.952783

\footnotetext{
* 1 Prof. Ph.D., Ondokuz Mayis University, Faculty of Education, Department of Educational Sciences, sbalci@,omu.edu.tr-0000-0001-9506-6528

** Ph.D., Ondokuz Mayis University, Faculty of Education, nurdan.cabuker@omu.edu.tr- 0000-0001-7976-8829

*** Assoc. Prof. Ph.D., Ondokuz Mayis University, Faculty of Education, Department of Special Education, meryem.vural@omu.edu.tr-0000-0002-7836-7289

***** Assist. Prof. Ph.D,. Ondokuz Mayis University, Faculty of Education, Department of Educational Sciences, hatice.epli@omu.edu.tr- 0000-0001-9122-1922
} 


\section{Introduction}

COVID outbreak that occurred in China in December 2019 affected the whole world within weeks. On March 11, 2019, with the first case in Turkey, several measures were taken to fight the outbreak in our country, as in the whole world. Schools at all levels started online education, and social areas with many people, such as shopping malls, movie theatres, and restaurants, were shut. Flexible and rotational working was started in private and official workplaces, and curfews were introduced. One of the groups most affected by the new regulations within the context of measures taken was university students. The rapid spread of the disease, isolation measures, transition to online education at universities (Cao et al., 2020), and insufficiencies in the online education system (Karadağ \& Yücel, 2020) negatively affected students' mental health. Considering the developmental period and developmental tasks of higher education students continuing their university education, it is said that they are one of the groups most affected by the measures taken and the new regulations introduced.

The possibility of loss deriving from the pandemic, the sudden changes in social life (Yeşildal \& Reyhanlığlu, 2020), the emergence of a threat to physical or vital integrity, death or threat of death (Ezerbolat \& Özpolat, 2016), events such as natural disasters, exposure to sexual harassment or rape, being diagnosed with a terminal illness, terrorist attacks, epidemics, accidents, and the loss of a loved one (Altan, 2013; Bellur, 2015; Yeşildal \& Reyhanlığlu, 2020) are defined as trauma. Throughout the COVID pandemic, the anxiety individuals feel for themselves and their loved ones, the uncertainty about the course and treatment of the disease, not being able to visit the relatives infected with the virus, or not being able to share the pain of relatives who experience a loss also cause trauma (Yeşildal \& Reyhanlığlu, 2020). However, traumas can positively and negatively affect individuals' lives (Arikan, 2007).

Positive changes that occur in individuals following negative life events are expressed as post-traumatic growth (Tedeschi \& Calhoun, 2004). Although traumatic events cause individuals to undergo negative experiences, they expand their perspectives about life and enable them to realize their personal and social resources (Park \& Fenster, 2004). The areas in which post-traumatic growth is experienced can occur at different levels for everyone. Post-traumatic growth occurs in three areas: self-perception, relationships, and the life philosophy (Güven, 2010; Tedeschi, Park \& Calhoun, 1998). Post-traumatic individuals emerge as individuals who understand the value of life by gaining awareness of their 
182S. B. Çelik, N. D. Çabuker, M. V. Batık \& H. Epli / Pamukkale University Journal of Education, 55, 180-202, 2022 mortality, vulnerability, and strong aspects. The self-awareness they gain strengthens their feelings of sensitivity, empathy, and compassion against others (Tedeschi et al., 1998). There is an increase in the effort and the tendency to help their existing relationships (Haselden, 2014). Following trauma, individuals question the value of life, there may occur changes in their priorities, and they may feel grateful for the things they were not previously aware of (Tedeschi et al., 1998). Tarım (2019) stated that realizing the value of life, positive transformations in relationships, high endurance, internal transitions, and turning loss into opportunity were factors that provided post-traumatic growth. Individuals who have high post-traumatic growth levels feel the power to overcome life problems they face, and they can cope with trauma more easily by focusing on the positive sides of trauma since they have coping skills (Özçetin-Üzar \& Hiçdurmaz, 2017). Therefore, it is thought that posttraumatic growth can act as a catalyst in reducing the negative effects of the COVID pandemic by improving the coping skills of individuals.

A study has stated that post-traumatic growth is associated with the perception of consistency, psychological resilience, and optimism (Tedeschi \& Calhoun, 2004). The concept of optimism, associated with post-traumatic growth, is a self-reported general expectation that good things happen more often than bad things (Zoellner \& Maercker, 2006). The relationships between optimism and trauma have been examined in individual groups who have experienced various difficulties. In their study, Benight and Bandura (2004) found that individuals who perceive that they may cope with trauma look at life more positively and expect good things to happen in their lives since they can control their environment. In addition, Broekhof et al. (2015) found evidence that a person's tendency to optimism can be attributed to specific environmental factors and that optimism is inversely correlated with all sub-types of childhood traumas. In addition, they stated that there is an association between positive mood and optimism, and optimism provides positive mood, high morale, persistence, overcoming negative traumatic symptoms, and effective problemsolving. Optimistic people generally explain the reasons of events they experience and use these explanations as a step to growth from distress (Fredrickson, 2001; Peterson \& Steen, 2012).

Optimism, which is defined as the tendency to expect good results in life (Urcuyo, Boyers, Carver \& Antoni, 2005), is the state of an individual's expecting positive situations rather than negative results in life regardless of the situations and conditions experienced. It is stated that optimism has a critical significance for positive feelings, morale, academic 
S. B. Çelik, N. D. Çabuker, M. V. Batık \& H. Epli / Pamukkale University Journal of Education, 55, 180-202, 2022183 achievement, effective problem solving, and long healthy life, and that is evaluated as an important way to get rid of traumas. Contrary to optimism, which is considered a feature of adapting to life, pessimism is evaluated as a mental inadequacy (Daco, 1989). It has been accepted that pessimism reflects social inadequacy, passivity, illnesses, failure, and depression (Peterson, 2000; Seligman, 1998). Optimistic individuals who strongly expect that everything in life will be fine despite difficulties and obstacles (Goleman, 2000) can prevent negative thoughts and logically review negative thoughts. They also feel comfortable and peaceful and look to the future with confidence. Tendency to optimism is a cognitive process acquired later (Scheier \& Carver, 1985).

There are two types of optimism: the first is optimism considered as a characteristic (dispositional optimism), and the second one is situational optimism. Individuals with dispositional optimism focus more on positive events while evaluating life events. Individuals with situational optimism expect good things to happen (Seligman, 1998). Individuals interact with countless events, cases, and people throughout their lives. Life events and people they interact with make positive or negative contributions to individuals' lives. Optimism has an important impact on individuals' coping with trauma. Susan NolenHoeksema (2000) stated that optimists who have lost their relatives tend to re-evaluate the loss positively to cope with the pain and solve the problem by taking social support. Optimistic individuals interpret trauma as a wake-up call to define the priorities in their lives. They realize the fragility of life and live in the present more. They become more tolerant of others and realize the strengths they did not know they had (Carr, 2016). Due to the uncertainty created by the COVID pandemic, it is thought that addressing the variables that have a protective function for a pandemic will be important for individuals and community health care.

The common theme in the results of studies in the literature is the growth that occurs in individuals after experiencing traumatic events. This brings to mind that optimism can serve a supportive function for creating meaning in life and positive growth in the face of stressful experiences. Therefore, this study aims to determine how the positive feelings preservice teachers experienced through optimism from the negative events during the COVID pandemic explain post-traumatic growth. It is thought that the results found in the study will contribute to the consideration of optimism as a coping strategy for post-traumatic growth in the process of regulating the psychological effects of the COVID pandemic, which 
184S. B. Çelik, N. D. Çabuker, M. V. Batık \& H. Epli / Pamukkale University Journal of Education, 55, 180-202, 2022 is a trauma that affects very large masses. In the light of all information, the questions of this study are:

1. Is there a significant relationship between the impact of the event (COVID), optimism, and post-traumatic growth?

2. Do the event's impact (COVID) and optimism significantly predict post-traumatic growth?

3. Do the impact of the event (COVID), post-traumatic growth, and optimism differ significantly in terms of gender, getting online psychological support, and the state of turning to spirituality?

\section{Method}

This study was carried out with teacher candidates studying at the education faculty of Ondokuz Mayis University in 2020. The study was designed by using a correlational survey model. This study examined the correlations between the impact of the COVID pandemic, post-traumatic growth, and optimism. This research was conducted with the permission of Ondokuz Mayıs University Social and Human Sciences Ethics Committee, with the decision dated 29/05/2020 and numbered 2020/307.

\section{Participants}

The study group consisted of 801 university students studying at Ondokuz Mayis University and was reached through the convenience sampling method. All the students studying in the Faculty of Education were sent an online survey during the distance education process. The preservice teachers who volunteered participated in the study.

In this study, $74.5 \%$ of the preservice teachers were female $(n=597)$, and $25.5 \%$ were male ( $\mathrm{n}=204) .52 .2 \%$ of the participants lived in a city, $33 \%$ lived in a town and $14.9 \%$ lived in a village. It was found that six preservice teachers were diagnosed with COVID, while a relative of $15.1 \%$ were diagnosed with COVID. The participants' ages ranged between 17 and 27 and the average age was 21.79 .

\section{Data Collection Tools}

The data in the study were collected with the "Impact of Event Scale, Posttraumatic Growth Inventory, Optimism Scale and Information Collection Form".

Impact of event scale (IOS) 
S. B. Çelik, N. D. Çabuker, M. V. Batık \& H. Epli / Pamukkale University Journal of Education, 55, 180-202, 2022185 The scale was developed by Horowitz, Wilner, and Alvarez (1979) and revised by Weiss and Marmar (1997) and Creamer, Bell, and Failla (2003). The revised form was adapted into Turkish by Çorapçığlu, Yargıç, Geyran, and Kocabaşoğlu (2006) and aims to measure to what extent difficulties encountered after a stressful and traumatic experience make individuals' lives difficult. The purpose of the scale in this study is to measure the traumatic impact the COVID pandemic may cause on preservice teachers, the level of this traumatic impact, and its relationship with the other variables. The scale consists of three subdimensions as "intrusion, avoidance and hyperarousal" and 22 items. In the scale with a 5Likert type scoring, the items are scored between " $0=$ not at all $4=$ extremely". The lowest score one can get from the scale is 0 , while the highest is 88 . A high score from the scale shows that impact of event is high. Cronbach Alpha internal consistency coefficient of the scale is .94 (Çorapçıoglu et al., 2006). In the present study, Cronbach Alpha internal consistency coefficient was calculated as .91.

\section{Post-traumatic growth inventory (PTGI)}

The scale developed by Tedeschi and Calhoun (1996) was adapted into Turkish by Kağan, Güleç, Boysan, and Çavuş (2012). It is used to find out to what extent traumatic experiences in individuals' lives lead to positive changes in their lives. The inventory includes three subdimensions as "changes in perceptions of self, changes in the philosophy of life and changes in relationships with others" and a total of 21 items. In the scale with a 6-Likert type scoring, the items are scored between" $0=$ not at all and $5=$ to a very great degree". The lowest score one can get from the scale is 0 , while the highest score is 105 . A high score from the scale shows that post-traumatic growth is high. Cronbach Alpha internal consistency coefficient of the scale is .92. Test-retest correlation coefficient is .83 (Kağan et al., 2012). In the present study, Cronbach Alpha internal consistency coefficient was calculated as .95.

\section{Optimism scale (OS)}

The scale, which was developed by Balcı and Y1lmaz (2002) in Turkish culture, measures individuals' optimism levels. The scale has a single sub-dimension and includes 24 items. In the 4-Likert type scale, the items are scored between " $1=$ not like me at all and $4=$ very much like me". The lowest score one can get from the scale is 24 , while the highest score is 96. A high score from the scale shows high level of optimism. Cronbach Alpha internal consistency coefficient of the scale is .96 , while test-retest correlation coefficient is .61 (Balc1 and Y1lmaz, 2002). In the present study, Cronbach Alpha internal consistency coefficient was calculated as .93 . 


\section{Information collection form}

The researchers prepared the form included questions regarding information about the participants' age, gender, department, place of residence, status of getting diagnosed with COVID, and participation in distance education.

\section{Data Collection}

First, the required permissions were taken from the Social and Human Sciences Ethics Committee. The links of the measurement instruments prepared via Google forms were sent to all preservice teachers who participated in distance education. The preservice teachers who volunteered to participate in the study filled in the survey forms online. It took approximately 15 minutes to answer the survey form.

\section{Data Analysis}

First, Mahalanobis distance was measured, and the outliers were determined. According to this, three outliers were found and the analyses were made on 801 data by excluding these three data. Normality, linearity, and covariance assumptions were tested for multivariate analyses to be performed. Kurtosis and skewness values were calculated respectively as .17 and .62 for the impact of events, as -.76 and -.01 for post-traumatic growth, and as .03 and .65 for optimism. Scatter diagrams of all univariate combinations were examined, and it was found that all of the scatters were elliptical or close to elliptical. When the residual graphs of the variables were examined, it was found that the variables gathered around a linear axis and linearity assumption was met. It was found as a result of Box's $M$ test that the assumption of homogeneity of variances was met (Box's M=43.73, p=.058). In the light of all this data, it was found that all assumptions were met for multivariate analyses. In data analysis, Pearson moments correlation analysis, hierarchical regression, one-way MANOVA and two-way MANOVA were conducted.

\section{Results}

Table 1 shows preservice teachers' impact of the event (COVID pandemic), post-traumatic growth and optimism mean scores, and standard deviation values. There is a weak positive correlation between the impact of the event and post-traumatic growth $(r=.09, \mathrm{p}<.01)$; a weak negative correlation between the impact of event and optimism $(r=-.31, p<.01)$ and a moderate positive correlation between post-traumatic growth and optimism $(r=.49, \mathrm{p}<.01)$. 
Table 1. Correlation coefficients, means and standard deviation values

\begin{tabular}{llllll}
\hline Variables & M & Sd & $\mathbf{1}$ & $\mathbf{2}$ & $\mathbf{3}$ \\
\hline Impact of event (1) & 31.71 & 16.62 & - & $-.31^{*}$ & $.09 *$ \\
Optimism (2) & 49.89 & 23.90 & - & - & $.49 *$ \\
Post-traumatic growth (3) & 70.89 & 14.65 & & & \\
\hline$* p<.01$ & & & &
\end{tabular}

\section{Regression analysis}

Hierarchical regression analysis was performed to determine the variables that predict posttraumatic growth in preservice teachers (Table 2). According to the results, it was found that the variables of optimism $(\mathrm{t}=18.62, \mathrm{p}<.001)$ and impact of the event $(\mathrm{t}=8.69, \mathrm{p}<.001)$ significantly predicted post-traumatic growth. Optimism predicted $24 \%$ of posttraumatic growth $\left(\mathrm{R}^{2}=.24, \mathrm{~F}_{\text {change }}(1,799)=257.08, \mathrm{p}=.000\right)$. In addition, the effect of the event contributes $6 \%$ to the total variance $\left(\Delta \mathrm{R}^{2}=.06, \mathrm{~F}_{\text {change }}(1,798)=75.64, \mathrm{p}=.000\right)$. According to $\beta$ values of the variables, "optimism" in the first place and "impact of the event" in the second place significantly predicted post-traumatic growth. In other words, $24 \%$ of posttraumatic growth was explained by optimism and $6 \%$ by the impact of the event; these two variables predicted $31 \%$ of post-traumatic growth in preservice teachers $\left(\mathrm{R}^{2}=.31, \mathrm{~F}_{(2,798)}\right.$ $=178.37, \mathrm{p}=.000)$.

Table 2. Hierarchical regression analysis results

\begin{tabular}{|c|c|c|c|c|c|c|c|c|}
\hline & $\begin{array}{c}\text { Predictive } \\
\text { variable }\end{array}$ & $\begin{array}{l}\text { Reg. } \\
\text { coef. }\end{array}$ & $\begin{array}{l}\text { Std. } \\
\text { error }\end{array}$ & $\boldsymbol{\beta}$ & $\mathbf{t}$ & $\mathbf{R}$ & $\mathbf{R}^{2}$ & $\mathbf{F}$ \\
\hline 1 & $\begin{array}{l}\text { Fixed } \\
\text { Optimism }\end{array}$ & $\begin{array}{l}-7.21 \\
.80\end{array}$ & $\begin{array}{l}3.63 \\
.05\end{array}$ & -4 & $\begin{array}{l}-1.98 * \\
16.0 * *\end{array}$ & .49 & .55 & 257.08 \\
\hline 2 & $\begin{array}{l}\text { Fixed } \\
\text { Optimism }\end{array}$ & $\begin{array}{l}-28.98 \\
.94 \\
.39\end{array}$ & $\begin{array}{l}4.28 \\
.05 \\
.04\end{array}$ & $\begin{array}{l}- \\
.57 \\
.27\end{array}$ & $\begin{array}{l}6.76 * * \\
18.62 * * \\
8.69 * *\end{array}$ & .55 & .31 & 178.37 \\
\hline & $\begin{array}{l}.56, \mathrm{R}^{2}=.31 \\
<.05, * * \mathrm{p}<.00\end{array}$ & $98)==1$ & $\mathrm{p}=$ & & & & & \\
\hline
\end{tabular}


188S. B. Çelik, N. D. Çabuker, M. V. Batık \& H. Epli / Pamukkale University Journal of Education, 55, 180-202, 2022

\section{Multivariate Variance Analysis}

According to the One-Way MANOVA result (Table 3), which was conducted to determine the effect of the event (COVID epidemic), post-traumatic growth, and the differentiation of optimism by gender, the main effect of gender on the effect of the event, post-traumatic growth and optimism scores was found to be significant $(\lambda=.97, F(3,797)=6.48, p<.001)$. Preservice teachers' mean impact of event (COVID-19 pandemic) scores differed significantly between females and males $\left[F_{(1,799)}=9.94, \mathrm{p}<.01\right]$. According to these results, it can be said that females are significantly more affected by the COVID-19 pandemic than males. It was also found that post-traumatic growth mean scores of preservice teachers differed significantly in terms of gender $\left[F_{(1,799)}=12.03, \mathrm{p}<.01\right]$, and females had significantly higher post-traumatic growth levels than males. Although females' posttraumatic growth levels are significantly higher than males', their partial meta-square values $\left(\Pi^{2}=.024\right)$ showed a very low effect. Optimism levels of preservice teachers were not found to differ significantly in terms of gender $\left[F_{(1,799)}=.97, \mathrm{p}>.05\right]$.

Table 3. One-way MANOVA results

\begin{tabular}{|c|c|c|c|c|c|c|c|}
\hline Variable & Source & $\mathbf{n}$ & $\mathbf{M}$ & Sd & df & $\mathbf{F}$ & Partial $\eta^{2}$ \\
\hline \multirow[t]{3}{*}{ Impact of event } & Female & 597 & 32.74 & 16.63 & \multirow{3}{*}{1} & \multirow{3}{*}{$8.94 *$} & \multirow{3}{*}{.011} \\
\hline & & & & & & & \\
\hline & Male & 204 & 28.73 & 16.24 & & & \\
\hline \multirow[t]{3}{*}{ Optimism } & Female & 597 & 71.26 & 14.56 & \multirow{3}{*}{1} & \multirow{3}{*}{.97} & \multirow{3}{*}{.001} \\
\hline & & & & & & & \\
\hline & Male & 204 & 70.09 & 14.91 & & & \\
\hline \multirow{3}{*}{$\begin{array}{l}\text { Posttraumatic } \\
\text { growth }\end{array}$} & Female & 597 & 51.59 & 23.68 & \multirow{3}{*}{1} & \multirow{3}{*}{$12.03 *$} & \multirow{3}{*}{.015} \\
\hline & & & & & & & \\
\hline & Male & 204 & 44.92 & 23.89 & & & \\
\hline \multicolumn{8}{|c|}{$\left(\right.$ Wilk's Lambda $(\lambda)=.97$, Partial $\left.\eta^{2}=.024, F(3,797)=6.48, p=.000\right)$} \\
\hline \multicolumn{8}{|c|}{$* \mathrm{p}<.01, * * \mathrm{p}<.001$} \\
\hline
\end{tabular}

According to the results of the Two-Way MANOVA (Table 4), which was conducted to determine the effect of the event (COVID epidemic), post-traumatic growth, and the 
S. B. Çelik, N. D. Çabuker, M. V. Batık \& H. Epli / Pamukkale University Journal of Education, 55, 180-202, 2022189 differentiation status of optimism according to online psychological support and orientation to spirituality (Table 4), the status of receiving online psychological support and orientation to spirituality; it is understood that there is no common effect on the effect of the event, posttraumatic growth and optimism $\left(\lambda=.99\right.$, Partial $\left.\Pi^{2}=.007, \mathrm{~F}_{(3,795)}=1.89, \mathrm{p}>.05\right)$.

Table 4. Two-way MANOVA results

\begin{tabular}{|c|c|c|c|c|c|c|}
\hline $\begin{array}{l}\text { Independent } \\
\text { variable }\end{array}$ & Source & $\begin{array}{l}\text { Sum of } \\
\text { squares }\end{array}$ & Sd & $\begin{array}{l}\text { Mean of } \\
\text { squares }\end{array}$ & $\mathbf{F}$ & Partial $\eta^{2}$ \\
\hline \multirow{5}{*}{ Impact of event } & O.P.S. ${ }^{(1)}$ & 9914.84 & 1 & 9914.84 & $37.71 * *$ & .045 \\
\hline & T.S. ${ }^{(2)}$ & 1121.76 & 1 & 1121.76 & $4.26^{*}$ & .005 \\
\hline & O.P.S. ${ }^{*}$ T.S. & 1087.29 & 1 & 1087.29 & $4.13^{*}$ & .005 \\
\hline & Error & 209513.1 & 797 & 262.87 & & \\
\hline & Total & 1026575.0 & 801 & & & \\
\hline \multirow{5}{*}{ Optimism } & O.P.S. & 3031.32 & 1 & 3031.32 & $15.05 * *$ & .019 \\
\hline & T.S. & 1143.64 & 1 & 1143.64 & $5.67 *$ & .007 \\
\hline & O.P.S.* T.S. & 72.47 & 1 & 72.47 & .36 & .000 \\
\hline & Error & 160532.44 & 797 & 201.42 & & \\
\hline & Total & 4205383.0 & 801 & & & \\
\hline \multirow{5}{*}{$\begin{array}{l}\text { Posttraumatic } \\
\text { growth }\end{array}$} & O.P.S. & 435.49 & 1 & 435.49 & .89 & .001 \\
\hline & T.S. & 9962.81 & 1 & 9962.81 & $20.5 * *$ & .025 \\
\hline & O.P.S. ${ }^{*}$ T.S. & 414.17 & 1 & 414.17 & .85 & .001 \\
\hline & Error & 387274.89 & 797 & 485.91 & & \\
\hline & Total & 2451103.0 & 801 & & & \\
\hline \multicolumn{7}{|c|}{$\left(\lambda=.99\right.$, Kismi $\left.\eta^{2}=.007, \mathrm{~F}_{(3,795)}=1.89, \mathrm{p}=.12\right)$} \\
\hline$* p<.05, * * p<.00$ & ${ }^{(1)}$ O.P.S. $=\mathrm{O}$ & psycholog & & & . & ritu \\
\hline
\end{tabular}

The joint effect of receiving online psychological support and turning to spirituality on being affected by the event (COVID epidemic) is significant $\left(\mathrm{F}_{(1,797)}=4.13, \mathrm{p}<.05\right)$, and this effect is very small according to partial eta square values $\left(\Pi^{2}=.007\right)$. Among the teacher candidates who receive online psychological support, the level of being affected by the event is lower than those who do not turn to spirituality. Among the teacher candidates who do not 
190S. B. Çelik, N. D. Çabuker, M. V. Batık \& H. Epli / Pamukkale University Journal of Education, 55, 180-202, 2022 receive online psychological support, the event's level does not differ between those who turn to spirituality and those who do not. Preservice teachers' impact of event (COVID pandemic) levels differ significantly in terms of getting online psychological support $\left[\mathrm{F}_{(1}\right.$, $797)=37.71, \mathrm{p}<.001]$ and the state of turning to spirituality $\left[\mathrm{F}_{(1,797)}=4.26, \mathrm{p}<.05\right]$. According to Bonferroni test results, the mean impact of event scores of preservice teachers getting online psychological support $(\mathrm{M}=46.67, \mathrm{SD}=2.5)$ is significantly higher than those who are not $(\mathrm{M}=30.86, \mathrm{SD}=.59)$. The mean impact of event scores of preservice teachers who turn to spirituality $(M=36.11, S D=1.86)$ is significantly lower than those who do not $(M=41.43$, $\mathrm{SD}=1.77)$.

The joint effect of receiving online psychological support and turning to spirituality

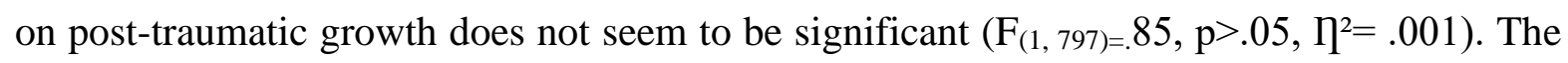
post-traumatic growth levels of preservice teachers who turn to spirituality do not differ between those who receive online psychological support and those who do not. Whether they receive online psychological support or not, the post-traumatic growth scores of preservice teachers turning to spirituality are higher than other groups. The preservice teachers who do not receive online psychological support and do not turn to spirituality have lower post-traumatic growth levels. Although online psychological support and turning to spirituality do not commonly affect post-traumatic growth, turning to spirituality stands out as a more determinant variable. While the post-traumatic growth levels of preservice teachers do not differ significantly in terms of the state of getting online psychological support $\left[\mathrm{F}_{(1,797)}=.89, \mathrm{p}>.05\right]$; they are found to differ significantly in terms of the state of turning to spirituality $\left[\mathrm{F}_{(1,797)}=20.5, \mathrm{p}<.001\right]$. According to Bonferroni test results, mean post-traumatic growth levels of preservice teachers who turned to spirituality $(\mathrm{M}=60.75$, $\mathrm{SD}=2.54)$ are significantly higher than those who do not $(\mathrm{M}=44.91, \mathrm{SD}=2.41)$.

It was determined that the joint effect of receiving online psychological support and turning to spirituality on optimism is not significant $\left(\mathrm{F}_{(1,797)}=.36, \mathrm{p}>.05, \eta^{2}=.000\right)$. Among the preservice teachers who receive online psychological support or who do not, the optimism levels of those who turn to spirituality are higher than those who do not. In addition, the optimism levels of preservice teachers who both receive online psychological support and turn to spirituality are lower than those who do not receive online psychological support. Although online psychological support and turning to spirituality do not have a joint effect on optimism, it is seen that they have an independent effect on optimism. Optimism levels of preservice teachers are found to differ significantly in terms of their states of getting online 
S. B. Çelik, N. D. Çabuker, M. V. Batık \& H. Epli / Pamukkale University Journal of Education, 55, 180-202, 2022191 psychological support $\left[\mathrm{F}_{(1,797)}=15.05, \mathrm{p}<.001\right]$ and turning to spirituality $\left[\mathrm{F}_{(1,797)}=5.67\right.$, $\mathrm{p}<.05]$. According to Bonferroni test results, mean optimism levels of preservice teachers who get online psychological support $(\mathrm{M}=63.19, \mathrm{SD}=2.19)$ are significantly lower than those of preservice teachers who do not $(\mathrm{M}=71.93, \mathrm{SD}=.52)$. Optimism levels of preservice teachers who turn to spirituality are significantly higher than those of preservice teachers who do not $(\mathrm{M}=64.87, \mathrm{SD}=1.55)$.

In short, it can be said that preservice teachers who get online psychological support have higher impact of event (COVID pandemic) levels and lower optimism levels. It can be stated that preservice teachers who turn to spirituality during the pandemic have lower impact of event levels and higher post-traumatic growth and optimism levels.

\section{Discussion}

This study, which examines the effect of the event (COVID epidemic), post-traumatic growth and optimism in preservice teachers, shows that optimism and the effect of the event significantly predict post-traumatic growth. According to the effect size of the regression analysis results, it is found that the effect of the event and the predictive power of optimism on post-traumatic growth differ. Accordingly, when considered in terms of effect sizes; while optimism has the greatest effect, it is followed by the effect of the event. A positive beta value indicates that the relationship between them is linear. In other words, it reveals that as the scores of optimism and the effect of the event increase, the scores of posttraumatic growth also increase. The traumatic experience of the COVID epidemic that has occurred naturally and has spread over a wide period and the fact that it poses a threat to the lives of people worldwide may have been effective in getting this result. In other words, since sudden traumatic events have a more acute effect than deliberate and purposeful traumatic events, its severity may have become of secondary importance. Both past and current research results reveal that optimism can be considered as a coping strategy and that optimism can be effective in the development of post-traumatic growth in the process of transforming the results of the COVID epidemic into positive, which is a mass trauma that threatens the individual's life, and that is uncontrollable.

Many studies in the literature show parallelism with the findings of this study on post-traumatic growth and optimism (Bozo, Gündoğdu \& Büyükaşık-Çolak, 2009; Britton, LaLonde, Oshio \& Taku, 2019, Helgeson, Reynolds \& Tomich, 2006; Kraman \& Tarım, 2018; Maercker, 2010; Prati \& Pietranton, 2009). Similarly, Tedeschi and Calhoun (2004) found a positive correlation between optimism and post-traumatic growth scores, and they 
192S. B. Çelik, N. D. Çabuker, M. V. Batık \& H. Epli / Pamukkale University Journal of Education, 55, 180-202, 2022 emphasized the effects of both the concepts of optimism and post-traumatic growth on cognitive processes. In other words, they reported that optimistic individuals could focus their attention on their resources that play an important role in coping and getting away from uncontrollable or unsolvable problems. In another similar study dealing with the relationship between psychological well-being and post-traumatic growth in a population affected by a natural disaster, it has been seen that optimism has an important function in minimizing the effects of disaster (Garcia Martinez, Reyes \& Solar, 2014). Acquaye (2016), in his study investigating the relationship between optimism, post-traumatic growth, and religious commitment in Liberian refugees, has revealed a significant relationship between the impact of war-related events and post-traumatic stress disorder. Similarly, Zoellner, Rabe, Karl, and Maercker (2008) in their study investigating the effects of the severity of trauma and optimism on post-traumatic growth, have revealed the effects of different interactions between the severity of post-traumatic stress disorder and optimism and the mitigating role of post-traumatic growth on the severity of post-traumatic stress disorder.

There are also studies conducted using different variables related to the optimism levels of individuals during the pandemic process. Çelebi, Kaya, and Y1lmaz (2021) stated that the effects of the COVID pandemic were felt in different areas and that they thought that one of the basic emotions in individuals in this process was anxiety. The study aimed to determine the relationship between coping with humor, health anxiety, and optimism and to explore the mediating role of optimism in the relationship between coping with humor and health anxiety. As a result of mediation analysis, it was found that optimism has a partial mediator role in the relationship between coping with humor and health anxiety. Tongar, Ülküer, Geçer, Yıldırım, and Akgül, (2021) examined the factors affecting the level of optimism of mothers with children aged 3-6 years during the COVID pandemic. Mothers' levels of optimism were affected by variables such as education, age, income, number of children, and working, but not by marital status. It was found that the level of optimism increased with the increase in marital satisfaction and happiness and decreased with the increase in the use of social media and the duration of watching television. Atar, Urgan, and Erdoğan (2020) in their studies aiming to determine the levels of optimism, pessimism, and life satisfaction in the first three months of the COVID epidemic, have found that the general optimism and life satisfaction levels are higher than the general pessimism level; the pessimism level of women is higher than men; the life satisfaction level of married 
participants is higher than single participants, and the optimism and life satisfaction level of the white-collar working group is higher than the other participants.

The present study results show that individuals who use their coping skills effectively in the face of the COVID pandemic emerge from this process by getting stronger. In other words, it can be said that individuals who try to see this process with its positive aspects are more advantageous in transforming the effects of trauma into positive. Optimism has the feature of determining how to approach problems in life, deal with difficulties, and be affected by traumatic events. A personal trait such as optimism promotes post-traumatic growth through coping reactions that may also reinforce feelings for holding onto life. It can also be said that optimistic individuals tend to realize the positive changes about themselves and feel their post-traumatic success more. This, in turn, may have created a positive effect on growth after traumatic experiences.

According to another result of the study, the main effect of gender on optimism and post-traumatic growth was significant. It was found that when compared with men, women were both more affected by the COVID pandemic and had higher post-traumatic growth levels. On the other hand, the optimism levels of preservice teachers did not differ significantly in terms of gender. This result of the present study is similar to the results of other studies in the literature (Jin, Xu, \& Liu, 2014; Zwahlen, Hagenbuch, Carley, Jenewein $\&$ Buchi, 2006). In a study which examined the negative and positive psychological effects that occurred after the attack on June 28, 2016, at Atatürk Airport on private security staff, Şahne (2018) concluded that female security officers had higher traumatic growth scores than male security officers and gender predicted post-traumatic growth significantly and moderately. Gender role stereotypes can explain the results of the present study. Gender role stereotypes are very effective in raising women and men to cope differently with the same stressors. In other words, the fact that women are encouraged to seek support or give support to others to cope with stressors may have been effective in this result.

On the other hand, unlike women, men's using a coping method such as emotional support during this process may be associated with weakness. For this reason, men's direct actionbased coping acts are a social expectation. Understanding the mechanisms about how women and men can provide growth after traumatic experiences will provide them support with turning this process into positive. Addressing the variables that can play a mediating role in this issue, that is, determining the variables that will be the source of post-traumatic 
194S. B. Çelik, N. D. Çabuker, M. V. Batık \& H. Epli / Pamukkale University Journal of Education, 55, 180-202, 2022 development of women and men separately will serve as a powerful catalyst that can be used to turn the negative effects of this process into positive.

As a result of the study, it was remarkable that preservice teachers who received online psychological support had a higher impact of event scores and lower post-traumatic and optimism levels. It would be misleading to interpret this result as preservice teachers being negatively affected by the psychological support. It is thought that individuals who are more negatively affected by this pandemic process resort to online psychological support more. Topkaya (2014) stated that increase in psychological distress increased the intention to receive psychological support and psychological distress level was an important variable that played a role in the intention to get psychological support.

According to another important result of the study, it was found that during the pandemic process, preservice teachers who turned to spirituality had the lower impact of event levels and higher post-traumatic growth and optimism levels;. In comparison, preservice teachers who got online psychological support had a higher impact of event levels and lower post-traumatic growth and optimism levels, and preservice teachers who got online psychological support had a higher impact of event levels. Similarly, Acquaye (2017) showed that in religious refugees with a high level of optimism, post-traumatic growth was high. Buxton (2011) showed that devotion to religion, optimism, and psychosocial intervention increased post-traumatic growth. Post-traumatic social support and spirituality are evaluated as an important factor in showing post-traumatic growth of individuals (Aric1 Özcan \& Arslan, 2020; Tedeschi et al., 1998; Y1lmaz, 2014; Yurtsever, 2018). The present study shows the protective function of turning to spirituality during the COVID pandemic and its positive effect on post-traumatic growth. This result of our study is very important in showing the necessity of supporting the spiritual aspect of humans in suppressing their worries to maintain their material presence. The trauma caused by the COVID pandemic causes people to question the value of life and create new values that prioritize the holiness of life. During an epidemic that poses a high risk to the continuity of life, people on the one hand, face the facts of the epidemic and, on the other hand, aim to protect from the negative effects of the pandemic process with spiritual rituals. Considering the duration and effects of the pandemic, it can be predicted that the fear of death can significantly increase the levels of turning to religious beliefs. In addition to the emergence of religious life rituals as a coping strategy, such a pandemic process which threatens the continuity of life and causes the fear of death in individuals can also lead to awareness of the transition from a world 
S. B. Çelik, N. D. Çabuker, M. V. Batık \& H. Epli / Pamukkale University Journal of Education, 55, 180-202, 2022195 order where materials are prioritized in the long term to a world where nature, environment and human values are prioritized.

\section{Limitations and Recommendations}

The most important limitation of the study is that the data includes cross-sectional results; in other words, it does not include longitudinal results. Since the COVID pandemic is a traumatic experience that is experienced over a long period, longitudinal studies are needed to understand its effects on post-traumatic growth in time. Another limitation of the study is the fact that there is no information about whether the participants experienced any loss during this process. In addition, this study was conducted with students studying only in the faculty of education. It will be important to repeat the study results in individuals with different sample groups and different age groups in terms of generalizability. The study's strength is that it is the first study that includes a level of impact from trauma-related with COVID pandemic, post-traumatic growth, and optimism together, and it is fundamental in terms of showing the possible effects of the COVID trauma process.

Considering both the past and the future of the COVID pandemic, continuous exposure of individuals to high levels of health threats may threaten their future physical and mental health. For this reason, there is a need to investigate the effects of psychoeducation studies and studies that show the relationship between the effects of such a long-term trauma, post-traumatic growth, and optimism. This is because of the post-traumatic growth experienced, the way individuals handle this process positively or negatively affects their levels of being influenced by the process. Handling the COVID pandemic in a pessimistic way may cause preservice teachers to experience desperation and thus to lose their strength to fight the existing situation. On the other hand, they can reinforce their strength to fight when they optimistically handle this process. The present study shows that traumatic events can also be a source for individuals to develop their optimistic thinking skills in negative situations. Based on this, employees in the field should focus not only on negative results but also on positive changes. It is important to consider the possibility that these positive changes will lead individuals to recover more quickly from the effects of the trauma in question. Therefore, it is thought that the results of the current study will contribute to the process of developing effective intervention strategies with both group counseling and individual counseling. Considering the effect of skills such as sharing experiences with others, having a positive perspective, optimism, realizing social support resources, and being able to use these resources effectively on developing post-traumatic growth; psychological 
196S. B. Çelik, N. D. Çabuker, M. V. Batık \& H. Epli / Pamukkale University Journal of Education, 55, 180-202, 2022 support programs including these skills will help provide post-traumatic growth (Bonanno, Westphal \& Mancini, 2011; Moreno \& Stanton 2013; Tomich, Helgenson \& Nowak Vache, 2005; Yanez et al., 2011). For this reason, it is recommended to prepare psychological support programs to increase the post-traumatic growth and optimism levels of individuals and to reduce the negative effects of the COVID pandemic process.

Ethical Approval: This research was conducted with the permission of the Ondokuz Mayls University Social and Human Sciences Ethics Committee, with the decision dated 29/052020 and numbered 2020/307.

Conflict Interest: There is no potential conflict of interest in this study.

Authors Contributions: All authors contributed equally.

\section{References}

Acquaye, H.E. (2016). The relationship among post-traumatic growth, religious commitment, and optimism in adult liberian former refugees and internally displaced persons traumatized by war-related events. Electronic Theses and Dissertations, 2004-2019, 5071.

Acquaye, H.E. (2017). PTSD, optimism, religious commitment, and growth as post-trauma trajectories: A structural equation modeling of former refugees. The Professional Counselor. 7,4, 330-348. http://dx.doi.org/10.15241/hea.7.4.330.

Altan, C. (2013). Üniversite öğrencilerinde travma sonrası gelişimi etkileyen faktörlerin incelenmesi. Unpublished master thesis, Haliç Üniversitesi, İstanbul.

Arıcı Özcan, N., \& Kaya, M. (2019). Travmatik yas sorununda aile dayanıklılı̆̆ programı'nın kadınların travma sonrası stres, yas ve aile dayanıklılı̆̆ı düzeylerine etkisi. Eğitim ve Bilim, 44,197, 121-138. http://dx.doi.org/10.15390/EB.2018.7663

Arıkan, G. (2007). Prevalence of traumatic events and determinants of posttraumaticgrowth in university students. Unpublished master thesis, Ortadoğu Techinal University, Ankara.

Balcı, S., \& Yılmaz, M. (2002). İyimserlik ölçeğinin geçerlilik ve güvenilirlik çalışması. Ondokuz Mayıs Üniversitesi Eğitim Fakültesi Dergisi, 14, 54-60. 
S. B. Çelik, N. D. Çabuker, M. V. Batık \& H. Epli / Pamukkale University Journal of Education, 55, 180-202, 2022197

Bellur, Z. (2015). Meme kanseri hastalarında çevresel, bireysel ve olaya dair faktörlerin travma sonrası gelişim ile ilişkisi. Unpublished master thesis, Mersin Üniversitesi, Mersin.

Benight, C.C., \& Bandura, A. (2004). Social cognitive theory of post-traumatic recovery: The role of perceived self-efficacy. Behavior Research and Therapy, 42, 1129-1148. http://dx.doi.org/10.1016/j.brat.2003.08.008

Bonanno, G.,A., Westphal, M., \& Mancini, A.D. (2011) Resilience to loss and potential trauma. Annual Review of Clinical Psychology, 7, 1, 1-25.

Bozo, Ö., Gündoğdu, E., \& Büyükaşık- Çolak, C. (2009). The moderating role of different sources of perceived social support on the dispositional optimism- post-traumatic growth relationship in postoperative breast cancer patients. Journal of Health

Psychology. 14, 7, 1009-1020. http://dx.doi.org/10.1177/1359105309342295

Britton, M., LaLonde, L., Oshio, A., \& Taku, K. (2019). Relationships among optimism, pessimism, and post-traumatic growth in the US and Japan: Focusing on varying patterns of perceived stressfulness. Personality and Individual Differences, 151, 1-6. http://dx.doi.org/10.1016/j.paid.2019.109513

Broekhof, R., Rius-Ottenheim, N., Spinhoven, P., van der Mast, R.C., Penninx, B.W., Zitman, F.G., \& Giltay, E.J. (2015). Long-lasting effects of affective disorders and childhood trauma on dispositional optimism. Journal of Affective Disorders, 175, 351-358. http://dx.doi.org/10.1016/j.jad.2015.01.022

Buxton A. (2011). Post-traumatic growth in survivors of breast cancer: The role of dispositional optimism, coping strategies, and psychosocial interventions. Unpublished doctoral thesis, University of Toronto, Toronto.

Carr, A. (2016). Pozitif psikoloji. (Çev. Ü. Şendilek). İstanbul: Kaknüs Yayınları.

Cao, W., Fang, Z., Hou, G., Han, M., Xu, X., Dong, J., et al. (2020). The psychological impact of the COVID epidemic on college students in China. Psychiatry Research 287,112934, 1-5. http://dx.doi.org/10.1016/j.psychres.2020.112934

Creamer, M., Bell, R., \& Failla, S. (2003). Psychometric properties of the impact of event scale - revised. Behaviour research and therapy, 41,12, 1489-1496. http://dx.doi.org 10.1016/j.brat.2003.07.010 
198S. B. Çelik, N. D. Çabuker, M. V. Batık \& H. Epli / Pamukkale University Journal of Education, 55, 180-202, 2022

Çorapçıŏglu, A., Yargıç, İ., Geyran, P., \& Kocabaşoğlu, N. (2006). Olayların Etkisi Ölçeği

(IES-R) Türkçe versiyonunun geçerlilik ve güvenilirliği. New Symposium Journal, 44,1, 14-22. http://dx.doi.org

Daco, P (1989). Çăğdaş psikolojinin olağanüstü başarıları. İstanbul: İnkılap Kitabevi.

Ezerbolat, M., \& Özpolat, A. (2016). Travma sonrası büyüme: Travmaya iyi yanından bakmak. Kriz Dergisi, 24,1, 1-10. http://dx.doi.org/10.1501/Kriz_0000000353

Fredrickson, B.L. (2001). The role of positive emotions in positive psychology: The broaden-and-build theory of positive emotions. American Psychologist, 56, 218-226. http://dx.doi.org/10.1080/10615806.2013.784278

Garcia Martinez, F.E., Reyes, A.R., \& Solar, F.C. (2014). Severity of trauma, optimism, posttaraumatic growth and well-being in survivors of a natural disaster. Universitas Psychologica, 13 (2), 575-584. http://dx.doi.org/10.11144/Javeriana.UPSY13-2.stop

Goleman, D. (2000). Duygusal Zeka. İstanbul: Varlık Yayınları.

Güven, K. (2010). Marmara depremini yaşayan yetişkinlerin algıladıkları sosyal destek düzeyleri ile travma sonrası gelişim ve depresyon düzeyleri arasındaki ilişkinin incelenmesi. Unpublished master thesis, Maltepe Üniversitesi, İstanbul.

Haselden, M. (2014). Üniversite ögrrencilerinde travma sonrası büyümeyi yordayan çeşitli değişkenlerin Türk ve Amerikan kültürlerinde incelenmesi: Bir model önerisi. Unpublished doctoral thesis, Hacettepe Üniversitesi, Ankara.

Helgeson, V.S., Reynolds, K.A., \& Tomich, P.L. (2006). A meta-analytic review of benefit finding and growth. Journal of Consulting and Clinical Psychology, 74, 5, 797-816. http://dx.doi.org/10.1037/0022-006X.74.5.797

Horowitz, M., Wilner, N., \& Alvarez, W. (1979). Impact of Event Scale: A measure of subjective stress. Psychosomatic Medicine, 41, 3, 209-218. http://dx.doi.org/10.1097/00006842-197905000-00004

Kağan, M., Güleç, M., Boysan, M., \& Çavuş, H. (2012). Hierarchical factor structure of the Turkish version of the Posttraumatic Growth Inventory in a normal population. TAF Preventive Medicine, 11, 5, 617-624. http://dx.doi.org/10.5455/pmb.1-1323620200

Karadağ, E., \& Yücel, C. (2020). Yeni tip Koronavirüs pandemisi döneminde üniversitelerde uzaktan eğitim: Lisans öğrencileri kapsamında bir değerlendirme 
S. B. Çelik, N. D. Çabuker, M. V. Batık \& H. Epli / Pamukkale University Journal of Education, 55, 180-202, 2022199 çalışması. Yüksekögretim Dergisi, 10,2, 192. http://dx.doi.org/10.2399/yod.20.730688

Karaman, Ö., \& Tarım, B (2018) Travma sonrası büyüme, sosyal problem çözme ve iyimserlik arasındaki ilişkilerin incelenmesi. Dicle Üniversitesi Sosyal Bilimler Enstitüsü Dergisi, 10, 20, 190-198.

Knaevelsrud, C., Liedl, A., \& Maercker, A. (2010). Post-traumatic growth, optimism and openness as outcomes of a cognitive-behavioural intervention for post-traumatic stress reactions. Journal of Health Psychology, 15, 7, 1030-1038. http://dx.doi.org/10.1177/1359105309360073

Moreno, P.I., \& Stanton, A.L. (2013). Personal growth during the experience of advanced cancer a systematic review. Cancer Journal, 19,5, 421-430. https://dx.doi.org/ 10.1097/PPO.0b013e3182a5bbe7

Özcetin-Üzar, Y.D., \& Hiçdurmaz, D. (2017). Post-traumatic growth and resilience in cancer experience. Current Approaches to Psychiatry, 9, 4, 2017, 388- 397. https://dx.doi.org/ 10.18863/pgy.290285

Nolen-Hoeksema, S. (2000). The role of rumination in depressive and mixed anxiety/ depressive symtoms. Journal of Abnormal Psyhology, 109, 3, 504-511.

Park, C., \& Fenster, J. (2004). Stress related growth: predictors of occurence and correlates with psychological adjustment. Journal of Social and Clinical Psychology, 23,2, 195-215. https://dx.doi.org/ 10.1521/jscp.23.2.195.31019

Peterson. C. (2000). The future of optimism. American Psychologist, 55, 1, 44-45. https://dx.doi.org/ 10.1037/0003-066X.55.1.44

Peterson, C., \& Steen, T. A. (2012). Optimistic explanatory style. In S. J. Lopez \& C. R. Snyder (Eds.), Oxford handbook of positive psychology (2nd ed., pp. 313-321). New York, NY: Oxford University Press.

Prati, G., \& Pietrantonu, L. (2009). Optimism, social support, and coping strategies as factors contributing to post-traumatic growth: A meta-analysis. Journal of Loss and Trauma, 14, 3, 64-388.

Scheier, M. F., \& Carver, C. S. (1985). Optimism, coping, and health: Assessment and implications of generalized outcome expectancies. Health Psychology, 4(3), 219247. https://doi.org/10.1037/0278-6133.4.3.219 
200S. B. Çelik, N. D. Çabuker, M. V. Batık \& H. Epli / Pamukkale University Journal of Education, 55, 180-202, 2022

Seligman, M. E. P (1998). Learned Optimism, Pocked Boks, New York.

Şahne, M. E. (2018). Atatürk havalimanı saldırısından 6 ay sonra personelde görülen travmatik stres belirtileri ve travma sonrası büyüme ile ilişkili faktörler. Unpublished master thesis, Üsküdar Üniversitesi, İstanbul.

Tarım, B. (2019). Yas yaşatısında travma sonrası büyüme. Unpublished master thesis Ordu Üniversitesi, Ordu.

Tedeschi, R. G., \& Calhoun, L. G. (1996). The Posttraumatic Growth Inventory: Measuring the positive legacy of trauma. Journal of Trauma Stress, 9, 455-471. https://dx.doi.org/ 10.1007/BF02103658

Tedeschi, R. G., Park, C. L., \& Calhoun, L. G. (1998). Post-traumatic Growth: Conceptual Issues. R. G. Tedeschi, C. L. Park, \& L. G. Calhoun içinde, Post-traumatic growth: Positive changes in the aftermath of crisis (s. 1-23). London: Lawrence Erlbaum Associates Publishers.

Tedeschi, R., \& Calhoun, L. (2004). Posttraumatic growth: Conceptual foundations and empirical evidence. Psychological Inquiry, 15,1, 1-18. https://dx.doi.org/ 10.1207/s15327965pli1501_01

Tomich, P.,L, Helgenson, V.,S. \& Nowak Vache, E., J. (2005). Perceived growth and decline following breast cancer: A comparison to age-matched controls 5-years later. Psychooncology, 14, 1018-1029. https://dx.doi.org/ 10.1002/pon.914

Topkaya, N. (2014). Psikolojik yardım alma niyetini yordamada demografik, bireysel ve çevresel faktörler. Türk Psikoloji Dergisi, 29,74, 1-11.

Tongar, K., Ulkuer, N., Geçer, E., Yıldırım, M., \& Akgül, Ö. (2021). Covid-19 Pandemisi sürecinde annelerin iyimserlik seviyesini etkileyen faktörlerin incelenmesi: Türkiye örneği. Dicle Üniversitesi Sosyal Bilimler Enstitüsü Dergisi, 28, 405-418. Retrieved from https://dergipark.org.tr/en/pub/diclesosbed/issue/65582/960368

Urcuyo, K. R., Boyers, A. E., Carver C. S., \& Antoni, M. H. (2005). Finding benefit in breast cancer: Relations with personality, coping, and concurrent well-being. Psychology and Health, 20, 175-192. http://dx. doi.org/10.1080/08870440512331317634.

Wagner, B., Knaevelsrud, C., \& Maercker, A. (2007). Post-Traumatic Growth and Optimism as Outcomes of an Internet-Based Intervention for Complicated Grief. 
S. B. Çelik, N. D. Çabuker, M. V. Batık \& H. Epli / Pamukkale University Journal of Education, 55, 180-202, 2022201

Cognitive Behaviour Therapy 156-161. https://dx.doi.org/10.1080/16506070701339713

Weiss, D., \& Marmar, C. (1997). The impact of event scale-revised. Wilson J., \& Keane T. (Eds.). In Assessing psychological trauma and PTSD. New York: Guilford Press.

Yanez, B., R., Stanton, A., L., Hoyt, M., A., Tennen ,H., \& Lechner S. (2011). Understanding perceptions of benefit following adversity: How do distinct assessments of growth relate to coping and adjustment to stressful events? Journal of Social and Clinical Psychology, 30,7, 699-721. https://dx.doi.org/ 10.1521/jscp.2011.30.7.699

Yazıcı Çelebi, G., Kaya, F., \& Yılmaz, M. (2021). Covid 19 pandemisi sürecinde mizahla başa çıkma ile sağlık anksiyetesi arasındaki ilişki: iyimserliğin aracı rolü. Süleyman Demirel Üniversitesi Sosyal Bilimler Enstitüsü Dergisi, 40, 24-48. Retrieved from https://dergipark.org.tr/en/pub/sbe/issue/62244/887432

Yeşildal, M., \& Reyhanlığlu, E. (2020). Salgın psikolojisi. İstanbul: Destek Yayınları.

Y1lmaz, M. (2014). Growth through traumatic loss: The effect of grief related factors, coping and personality on post-traumatic growth. Unpublished master thesis, Bilgi Üniversitesi, İstanbul.

Yurtsever, A. O. (2018). Akciğer kanseri hastalarında travma sonrası gelişim, tekrarlayıcı düşünme örüntüleri, algılanan sosyal destek ve belirsizliğe karşı tahammülsüzlük belirtileri arasındaki ilişkiler. Unpublished master thesis, Ege Üniversitesi, İzmir.

Zoellner, T., \& Maercker, A. (2006). Post-traumatic growth in clinical psychology: a critical review and introduction of a two component model. Clinical Psychology Review, 26, 626-653. https://dx.doi.org/ 10.1016/j.cpr.2006.01.008

Zoellner, T., Rabe, S., Karl, A., \& Maercker A. (2008). Post-traumatic growth in accident survivors: openness and optimism as predictors of its constructive or illusory sides. Journal of Clinical Psyhology, 64(3), 245-263. http://dx.doi.org/10.1002/jclp.20441

Zwahlen, D., Hagenbuch, N., Carley, M.I., Jenewein, J., \& Buchi, S. (2010). Post-traumatic growth in cancer patients and partners--effects of role, gender and the dyad on couples' post-traumatic growth experience. Psycho-oncology, 19(1), 12-20. https://dx.doi.org/10.1002/pon.1486 